\title{
The Relationship between Media in the Home and Family Functioning in Context of Leisure
}

Camilla J. Hodge

Brigham Young University - Provo

Follow this and additional works at: https://scholarsarchive.byu.edu/etd

Part of the Recreation Business Commons

\section{BYU ScholarsArchive Citation}

Hodge, Camilla J., "The Relationship between Media in the Home and Family Functioning in Context of Leisure" (2011). Theses and Dissertations. 3028.

https://scholarsarchive.byu.edu/etd/3028

This Thesis is brought to you for free and open access by BYU ScholarsArchive. It has been accepted for inclusion in Theses and Dissertations by an authorized administrator of BYU ScholarsArchive. For more information, please contact scholarsarchive@byu.edu, ellen_amatangelo@byu.edu. 
The Relationship between Media in the Home and Family Functioning in Context of Leisure

\title{
Camilla Jennifer Hodge
}

A thesis submitted to the faculty of

Brigham Young University in partial fulfillment of the requirements for the degree of

\author{
Master of Science
}

Ramon B. Zabriskie, Ph.D.

Gilbert Fellingham, Ph.D.

Sarah Coyne, Ph.D.

Neil R. Lundberg, Ph.D.

Department of Recreation Management and Youth Leadership

Brigham Young University

June 2011

Copyright (C) Camilla Jennifer Hodge

All Rights Reserved 


\begin{abstract}
The Relationship between Media in the Home and Family Functioning in Context of Leisure
\end{abstract}

\author{
Camilla Jennifer Hodge \\ Department of Recreation Management and Youth Leadership
}

Master of Science

The purpose of the study was to examine the relationship between media as family leisure and family functioning among families with at least one adolescent child. Specifically, this study examined the relationship between family functioning and media use, media connection, and media monitoring over time. Furthermore, because the data were nested in families, and because most family leisure research has been limited to individual-level analyses, this study incorporated mixed modeling into its analysis which accounted for family-level and individuallevel variance. The sample consisted of 500 families participating in the Flourishing Families (FFP) Project, a longitudinal study of inner-family life involving families with a child between the ages of 11 and 16. Multiple regression analysis indicated there was a significant negative relationship between media use and family functioning. Mixed model analysis further indicated there was a significant positive relationship between media connection, parental media monitoring, and family functioning, and this relationship was stable over time. These relationships were significant even when accounting for the variance explained by depression, anxiety, conflict, and other demographic variables. Findings support existing media effects and family leisure research. This research, however, goes beyond existing research in its mixed level analysis that accounted for family-level variance and in its analysis of time in the stability of the relationship between media variables and family functioning. Findings further suggest the importance in parental involvement in adolescent media use when explaining variance in family functioning.

Keywords: family functioning, media use, parental media monitoring, mixed model analysis 


\section{ACKNOWLEDGEMENTS}

I would like to thank the many people whose ideas, suggestions, hard work, and encouragement helped make this research possible. I would especially like to thank Dr. Ramon Zabriskie for his unfailing support and faith in me, and for the nickname he bestowed upon me that will outlive my time here at BYU. To Dr. Sarah Coyne and the Flourishing Families Project Committee, I am grateful for the opportunity to tap into such incredible data and resources. To Dr. Gilbert Fellingham, I am especially grateful for his many hours of statistics instruction and explanation. I wish the fish in his fish tank all the best. Also on my committee, Dr. Neil Lundberg, to whom I owe many of the incredible references and background reading I conducted as I embarked on this adventure. In addition to the outstanding faculty who have served on my committee, I wish to mention Dr. Brian Hill, who lent support and a listening ear on many occasions, and Dr. Stacy Taniguchi, who believed in my project from its humble beginnings in his research methods class.

To my dear parents, words cannot express the gratitude I feel for your love, long-distance phone calls, and sacrifices on my behalf. I would not be here were it not for your inspired guidance and counsel. A special thank you to the best cohort ever: Taralyn Clark, Courtney Peck Gosling, Kim Molyneux, and Shaun Cassidy Nua. An equally special thank you to my friends and unofficial mentors: Melissa Russell, Jessie Bennett, Rachel Adams McGovern, and Clive Haydon. To you and my cohort, thank you for the encouragement, the laughs, the faith, and the help and support. I am so grateful to my amazing friends Karen Cottle, Megan Rasmussen, Jennica Dorsey, and Kathryn Rappleye who time and again picked me up and set me on my feet when I felt I could go no further. Finally, to the dancers: never a dull day, never a disappointment. 


\section{Table of Contents}

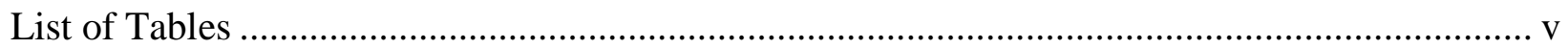

The Relationship between Media in the Home and Family Functioning in Context of Leisure .... 1

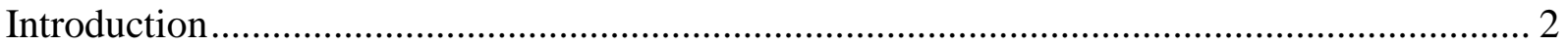

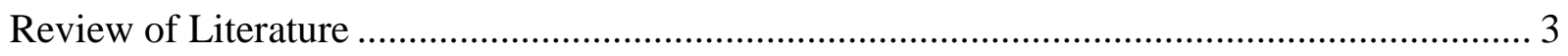

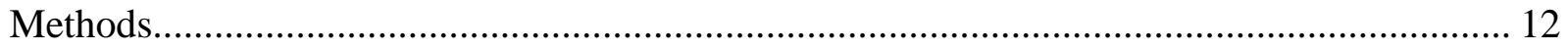

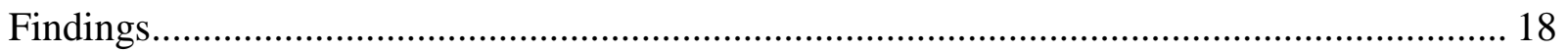

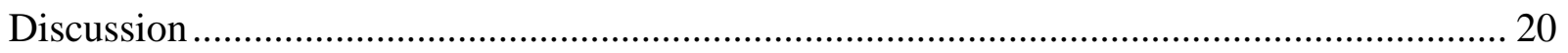

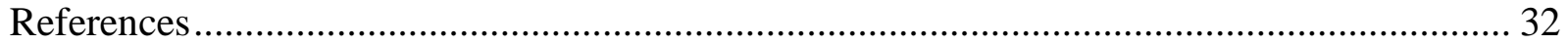

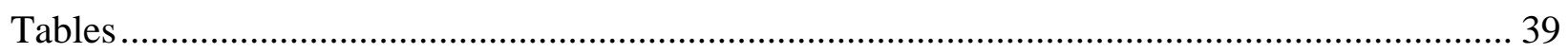

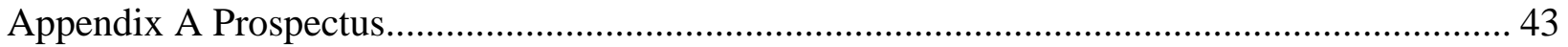

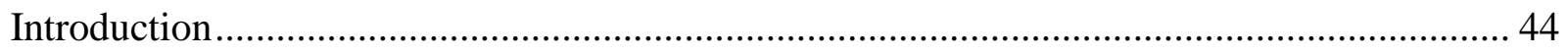

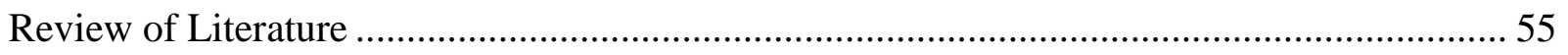

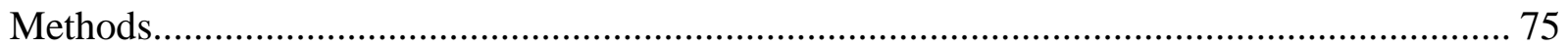

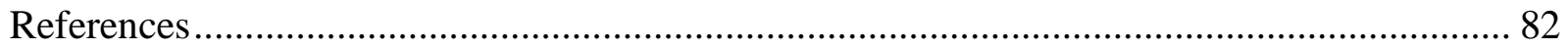




\section{List of Tables}

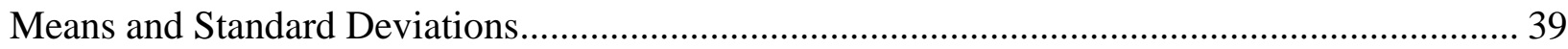

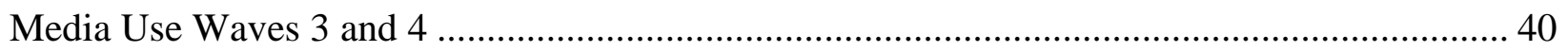

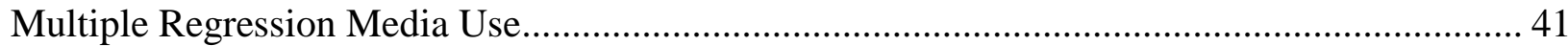

Mixed Model Media Connection and Parental Media Monitoring ......................................... 42 
The Relationship between Media in the Home and Family Functioning in Context of Leisure

Camilla J. Hodge

Ramon B. Zabriskie, Ph.D.

Gilbert Fellingham, Ph.D.

Sarah Coyne, Ph.D.

Neil R. Lundberg, Ph.D. 
The Relationship between Media in the Home and Family Functioning in Context of Leisure Research has clearly established a positive relationship between family leisure and outcomes such as family health and well-being, family functioning, and family life satisfaction (Agate, Zabriskie, Agate, \& Poff, 2009; Mactavish \& Schleien, 2004; Orthner \& Mancini, 1990; Poff, Zabriskie, \& Townsend, 2010; Zabriskie \& McCormick, 2001). Media claims a significant portion of leisure time in the United States for individuals, couples, and families and has become a mainstay of family and youth leisure (Brock, 2002; Daly, 1996; Rideout, Foehr, \& Roberts, 2010). Jeffres, Neuendorf, and Atkin (2003) estimate that about half of people's free time is spent in media consumption. Young people between the ages of 8 and 18 consume more than 7.5 hours of media each day, (Rideout et al., 2010). Computers - and the Internet access they provide — offer several other recreation options such as video games and online gaming — both of which are on the rise (Roy, 2009; Ryan, Rigby, \& Przybylski, 2006). Approximately 2 billion people worldwide use the Internet (Internet World Stats, 2010). The relationship between media use as family leisure and family functioning, however, is still largely unclear even though media use represents a significant proportion of family leisure activity.

Because research substantiates that family leisure involvement is related to family functioning, and media is one of the most common leisure activities, further studies are needed to understand the relationship between leisure media use patterns and family functioning. Furthermore, because most family leisure research has been limited to individual-level analyses, there is a need to use statistical methodology that appropriately accounts for family as well as individual variability. Therefore, the purpose of this study was to examine the relationship between media as family leisure and family functioning among families with at least one adolescent child. Specifically, this study examined the relationship between family functioning 
and media use, media connection, and media monitoring over time. Furthermore, because the data were nested in families, this study used the mixed model for analysis to account for both family-level and individual-level variance.

\section{Review of Literature}

\section{Family Functioning}

Researchers have named some fundamental measurable outcomes in seeking to better understand positive family attributes. One way researchers achieve this is by studying the construct of family functioning. Measuring family functioning is complex because it can be assessed in many ways (Epstein, Baldwin, \& Bishop, 1983). For the purposes of this research, family functioning will be assessed in context of the McMaster Model of Family Functioning as part of the family systems theory (Day et al., 2010; Miller et al., 2000).

Family systems theory. Systems theory is commonly used to interpret and understand family functioning. Systems theory suggests "all parts of the system are interconnected" and "understanding is only possible by viewing the whole" (White \& Klein, 2008, p. 156). In context of the family, systems theory suggests families are "greater than just a collection of individuals" because of the way they interact and how those interactions provide feedback (White \& Klein, p. 156).

The critical components of systems framework include: (a) system, or the relations between a set of objects and their attributes, meaning the system is separate from its environment but has an effect on it; (b) boundaries, which affect the flow of information and energy between the system and its environment; (c) rules of transformation, which is the equivalent of quid pro quo; (d) feedback, or the input and output of the system; (e) variety, or the ability to adapt to a changing environment; (f) equilibrium, or how a system achieves balance between input and 
output; (g) system levels, the varying degrees of prioritized goals; and (h) subsystems, various levels in a system such as parents and children (White \& Klein, 2008).

McMaster Model of Family Functioning. The McMaster Model of Family Functioning is a systems theory model, and also assumes "all parts of the family are interrelated" and parts of the family cannot be understood when separated from the rest of the family system (Miller et al., 2000, p. 169). Furthermore, the McMaster Model of Family Functioning posits family functioning cannot be understood by studying only individual members or subgroups of the family and that the influence of family structure and organization must be accounted for. Finally, the McMaster Model of Family Functioning states the influence of family interaction patterns must also be accounted for in order to understand family functioning (Miller et al.).

In order to meet those assumptions, the McMaster Model focuses on six dimensions of family life to accurately assess family functioning. Therefore the definition of family functioning comprises those six dimensions of "problem-solving, communication, roles, affective responsiveness, affective involvement, and behavior control” (Miller et al., 2000, p. 170). Problem-solving measures the ability of the family to resolve conflict and problems in such a way that maintains family functioning. Communication focuses on verbal exchanges in examining how information is shared within a family. Roles are the behavior patterns family members engage in to preserve and fulfill family functions. Affective responsiveness is the emotional ability of families to appropriately respond to stimuli while affective involvement is the degree to which the family exhibits "interest in and values the activities and interests of individual family members" (Miller et al., p. 171). Finally, behavior control is the manner in which a family addresses physically dangerous situations, psychological needs, and interpersonal socializing behavior (Miller et al.). 


\section{Leisure and Family Functioning}

Zabriskie and McCormick (2001) suggest leisure provides families the opportunity to reinforce and clarify crucial components of systems theory such as communication, interaction, and boundaries. These concepts are positively related to family functioning. Zabriskie and McCormick further suggest family leisure provides opportunities for families to adapt and interact with the family system. Because family leisure is interactive in nature, it provides an opportunity for families to explore and strengthen communication skills (Zabriskie \& McCormick).

Findings consistently indicate family leisure is positively related to family functioning, cohesiveness, satisfaction with family life, healthy couple relationships, healthy relationships between parents and their children, and family strength (Hawkes, 1991; Mactavish \& Schleien, 2004; Orthner \& Mancini, 1990; Poff et al., 2010; Zabriskie \& McCormick, 2001). Nutter, Zabriskie, Hill, and Eggett (2008), also reiterate family leisure involvement is related to higher levels of family functioning. Freeman and Zabriskie (2003) also stated "family leisure involvement was the strongest predictor of family functioning" and "families who participate in more family leisure also demonstrate higher levels of family functioning” (p. 86, p. 89). Furthermore, Zabriskie and McCormick asserted "besides family crisis, shared leisure may be one of the few experiences that bring family members together for any significant amount of time today" (p. 287). The majority of these studies, however, have utilized statistical analyses that account for individual-level variance only.

\section{Mass Media: Definition and Trends}

Media effects research has also historically utilized statistical analyses that account for individual-level variance only. To understand media effects research, and the relationship 
between media as leisure and family functioning, it is crucial to first understand what media are and its trends. The term "mass media" evokes images of newspapers, magazines, books, and other print media, as well as electronic forms of media, such as television, the Internet, and radio. Despite their diversity, mass media share four basic characteristics: (a) broad appeal, (b) speed, (c) availability, and (d) low unit cost (Stanton, 1949). The very term mass infers broad appeal to a large and diverse audience; mass media must attract an audience from varied demographic backgrounds. In terms of speed, mass media must be delivered in a timely manner. Availability also encompasses an element of time. Mass media must be available in various geographic locations, as well as at various times, and preferably communicates its messages through multiple sensory channels (i.e., audio and visual). Finally, mass media must be low-cost. Consuming media has become a way of life for most Americans. Mass media has become an integral part of day-to-day life and researchers estimate that about half of people's free time is spent in media use (Jeffres et al., 2003, p. 169). American youth between the ages of 8 and 18 are particularly heavy consumers engaging in an estimated average of about 8 hours of media use each day (Roberts \& Foehr, 2008).

The rapid spread of TV may have contributed to its archetypal mass media status. In 2001, the U.S. Census Bureau estimated there were 2.4 TV sets per household (Roberts \& Foehr, 2008). Brock (2007) stated decisively “TV viewing is America’s number one recreational pursuit" (p. 3). The Nielsen Company (2010), a leading media research group, reported Americans watch more than 35 hours of TV per week. Contributing to overall viewing time are new viewing technologies such as computers and mobile devices that have expanded the reach of television, making it more accessible. 
In addition to increased television ownership and viewing, Internet use has increased exponentially since it hit popular culture in 1994 (Montgomery \& Faloutsos, 2001). The number of Web users worldwide was approximately 2 billion in 2010 (Internet World Stats, 2010). Other forms of media are also experiencing similar growth trends. Online gaming and video games are one of the fastest growing forms of recreation (Roy, 2009).

Media is also quickly becoming an important facilitator of communication - a key factor in family functioning - between family members as well. Mediated communication includes text messages, e-mails, and Internet instant messaging (Pettigrew, 2009). Texting or "short typewritten messages or photographs sent via mobile phones," are "primarily used in personal relationships" to "commence, advance, maintain, or otherwise influence interpersonal relationships," is a particularly effective communication method that increases family members' sense of connectedness (Pettigrew p. 698). Similarly, e-mail and instant messaging are relationbased (Pettigrew). E-mail communication however, usually entails a longer, more detailed exchange of information that does not need an immediate response, and has been characterized for less close relationships (Kim, Kim, Park, \& Rice, 2007).

\section{Mass Media Effects}

Given media use trends, researchers "it makes common sense that anything that consumes so much money... and time...must have some impact on our lives" (Perse, 2001, p. 4). While it would be impossible to identify or categorize all types of potential media effects, studying them enables researchers to better understand how media effects occur and thereby enhance positive effects and lessen negative ones. Researchers have identified three types of media effects: cognitive, affective, and behavioral (Perse). Cognitive effects measure any effects related to learning and information acquisition; affective effects concern attitude formation, 
evaluations, and emotional reactions; and behavioral effects "are observable actions that are linked to media exposure" (Perse, p. 3). Existing research has further identified individual-level media effects in the following categories: (a) physical effects; (b) psychological and emotional effects; (c) effects on attitudes and values, emotions, and social behavior; and (d) effects on public opinion (Grimm, 2008; Kepplinger, 2008).

Parental media monitoring. Parental media monitoring may mediate such media effects. For example, Kennedy, Chen, and Charlesworth (2007) reported "the family communication climate may block some of the harmful effects of sexual media content on adolescents' moral development (p. 13). Warren, Gerke, \& Kelly (2002) suggest children are "best equipped to resist negative viewing effects when they become critical viewers"-a skill parents can help teach their children (p. 87).

In spite of empirical evidence suggesting the effectiveness of parental media monitoring, media monitoring practices are not employed by all parents (Warren et al., 2002). There are several determinants of parental media monitoring, including parental involvement, parents' attitudes toward media, and certain demographic indicators like child age (Nikken \& Jansz, 2006; Warren et al.). Kennedy et al. (2007) also reported overall maternal fatigue levels are related to less media monitoring and increased media time.

Much to the detriment of media effects research, the majority of study has dealt with media effects on the individual level, or micro-level, only. This is in fact, "a fallacy, however, to assume that all media effects are accumulations of individual-level effects. Scholars recognize that a focus solely on individual-level media effects can obscure more subtle societal-level effects" (Perse, 2001, p. 18). The most important effects may lie under-studied and undiscovered 
at the "societal, institutional, or cultural level" (Perse, p. 18). There is a need for more media effects extending beyond individual-level effects.

\section{Mass Media in Context of Leisure}

As established, mass media is commonly used as entertainment and leisure and media have influenced leisure patterns. In fact, Robinson (1969) stated "television has had a massive impact on American daily life, responsible for a greater rearrangement of time usage than the automobile" (p. 211). Media have caused a shift in cultural attitudes toward leisure (Brock, 2007).

Coffin (1948) published one of the first studies on television's effects on leisure. He reported families who owned television sets had lower rates of participation in out-of-home activities than families without sets. Furthermore, he noted television was replacing other previously engaged in "at-home" activities. Coffin predicted that as television became "more accessible to increasing numbers in the population it may bring with it noticeable effects on the family's activities in and out of the home" (p. 558).

To a certain extent, Coffin's (1948) predictions are coming to fruition. Media increasingly claim the leisure and recreation time of adults and youth because, as some researchers suggest, "new technologies have increased the mass media menu from which people may select" (Jeffres et al., 2003, p. 169). As this menu has grown, adults, youth, and families have learned to rely more on media for leisure and recreation. For example, video games have quickly risen in popularity and have "become the fastest growing form of human recreation" (Ryan et al., 2006, p. 347). Internet use has also increased; more than 266 million people in North America and nearly 2 billion people worldwide use the Internet (Internet World Stats, 2010). 
Media as family leisure. Media has clearly become a mainstay of the home and family, and "if we wish to understand family time, we need to understand 'family-plus-media."' (Daly, 1996, p. 76). Because media plays such a large role in family life, it is important to study and understand its relationship to family outcomes such as family functioning.

There are positive and negative aspects of using mass media as family leisure. Csikszentmihalyi and Kubey (1981) reported that among a sample of adults employed full-time, television watching was the least challenging activity they engaged in and the one that required the fewest skills. When watching television as a family however, the challenge increased considerably. Conversely, some research indicates watching television as a family creates a passive and one-dimensional experience (Daly, 1996). While still other research suggests television may be "linked to more frequent and positive family interactions" (Daly, p. 77). Families who can be categorized as heavy TV viewers have reported more time spent together than light viewers (Larson, Kubey, \& Colletti, 1989).

Spending more time together may not translate into an increase in family interaction. Kubey (1990) found family conversations decreased by $40 \%$ when watching TV as compared to all other non-television activities. Dempsey (2005) also reported that families interact more when engaged in activities other than watching TV, and that for every 1 hour increase in TV viewing, adolescents spend 6 minutes less in conversation with their parents. Brock (2007) clarified further, stating "watching television is a fundamentally solitary activity" (p. 20). Bovill and Livingstone (2001) agree and suggest that while television can be a family medium, the "future trajectory for television would seem to be towards increasingly solitary use" (p. 14). This suggests the way in which media is used by the family and its individual members (i.e., 
together or separately) may be an important factor in understanding the relationship between media and family.

The way in which couples use media as recreation is of particular importance to marital satisfaction. In the case of video gaming, "the ways in which couples participated and perceived the gaming activity" were more influential on marital satisfaction than overall time spent playing video games (Ahlstrom, Lundberg, Zabriskie, Eggett, \& Lindsay, 2009, p. 19). Furthermore, the way parents use media as leisure with their children is also of particular importance to their relationships. One study suggests daughters who play age-appropriate video games with their fathers report stronger mental health, a stronger sense of family connectedness, and exhibit better behavior (Coyne, Padilla-Walker, Stockdale, \& Day, 2011). Additionally, the use of other media such as texts, e-mail, and Internet-based instant messaging may facilitate communication between family members (Pettigrew, 2009). Thus, while the passiveness of television viewing may leave something to be desired in family leisure outcomes, perhaps other forms of media may actually facilitate positive outcomes. Still, the ability of media as leisure to produce positive outcomes such as increased family functioning remains in question.

Leisure research has clearly established a positive relationship between leisure and positive outcomes. Specifically, scholars have repeatedly found a positive relationship between family leisure and family functioning. Researchers, however, have largely ignored media use as family leisure even though media use represents a significant proportion of leisure activity. Furthermore, there is a gap in research concerning the effects of media on the family. While media effects research has clearly identified relationships between media and various outcomes such as physical health, psychological and emotional well-being, and attitudes and values, social behavior and public opinion, these have been examined solely on the individual level, focusing 
on youth and adults separately (Caroli et al., 2004; Grimm, 2008; Kepplinger, 2008;

Vandelanotte et al., 2009). Finally, because trends in media change over time, the relationship between media use and family functioning must be examined in context of the passage of time.

Therefore, the purpose of this study was to examine the relationship between media as family leisure and family functioning among families with at least one adolescent child. Specifically, this study examined the relationship between family functioning and media use, media connection, and media monitoring. Furthermore, because the data were nested in families, and because most family leisure research has been limited to individual-level analyses, this study incorporated mixed modeling into its analysis which accounted for family-level and individuallevel variance.

\section{Methods}

\section{Sample}

The participants for this study were taken from waves three and four of the Flourishing Families Project (FFP), a longitudinal study of inner-family life involving families with a child between the ages of 11 and 16. The sample was taken from a large northwestern city and consisted of 500 families (91.8\% retention from wave 1) with a child within the target range (330 two-parent families and 139 single-parent families). At wave four, participant children averaged 14.29 years of age, while mothers averaged 47.1 years and fathers averaged 49.3 years in age. Two hundred ninety-eight families (64.9\%) were of European American ethnicity, 56 (12.2\%) were African American, with a smaller number for Hispanics (1) and Asian Americans (4). Eighty-nine (19.3\%) families are categorized as multi-ethnic, based on a combination of two or more ethnicities among family members. In terms of parental education, $60.9 \%$ of mothers and approximately $69.7 \%$ of fathers had a bachelor's degree or higher. Related to yearly family 
income, $22.6 \%$ of families reported making less than $\$ 59,000 ; 32.8 \%$ reported income in the $\$ 60,000-99,000$ range; $29.9 \%$ reported income in the $\$ 100,000-149,000$ range, with another $14.7 \%$ making $\$ 150,000$ or more per year. Approximately $32 \%$ of single parents had never been married, $8.7 \%$ were separated, $49.3 \%$ were divorced, and $4.3 \%$ were widowed (Day et al., 2010).

\section{Data Collection Procedures}

Participant families for the FFP were selected from a large northwestern city and a midsized western city. They were interviewed during the first eight months of 2007. Families were primarily recruited using a purchased national telephone survey database (Polk Directories/ InfoUSA). This database claims to contain 82 million households across the United States and has detailed information about each household, including presence and age of children. Families identified using the Polk Directory were selected from targeted census tracts that mirrored the socio-economic and racial stratification of reports of local school districts. All families with a child between the ages of 10 and 14 living within target census tracts were deemed eligible to participate.

Eligible families were subsequently contacted directly using a multi-stage recruitment protocol. First, a letter of introduction was sent to potentially eligible families. Second, interviewers made home visits and phone calls to confirm eligibility and willingness to participate in the study. Once eligibility and consent were established, interviewers made an appointment to come to the family's home to conduct an assessment interview.

In addition to the random selection protocol used with the survey database, families were recruited through family referral. At the conclusion of their in-home interviews, families were invited to identify two additional families in the recruitment area that matched study eligibility. This type of limited-referral approach permitted researchers to identify eligible families in the 
targeted area that were not found in the Polk Directory. The Polk Directory national database was generated using telephone, magazine, and Internet subscription reports; therefore, families of color (especially those of lower socio-economic status) were underrepresented in the database. By broadening our approach and allowing for some limited referrals, we were able to significantly increase the social-economic and ethnic diversity of the sample.

Data were collected from both parents (in the case of a two-parent household) and from one child. Additionally, data were collected in waves with one year between each wave.

\section{Instrumentation}

The McMaster Family Assessment Device (FAD) was used to measure family functioning (Epstein et al., 1983). The Media in the Home scale was developed specifically for the FFP and was used to measure media connection and media use from a youth perspective. The parental media monitoring scale measured parent and youth estimations of parental engagement in youth media regulation. Finally, demographic and other variables of interest were collected.

FAD. Elements of family functioning were measured using the FAD (Epstein et al., 1983). The FAD is made up of seven subscales with a total of 53 items (Epstein et al.). A revised version of the FAD was used consisting of 20 items, including the entire General Functioning and Affective Responsiveness subscales and two items from the Affective Involvement subscale for the sake of questionnaire brevity. Respondents answered how much they agreed or disagreed with statements about their family using a four-point Likert scale ranging from strongly disagree to strongly agree, with higher scores indicating better family functioning (Day et al., 2010). 
Initial evidence of construct validity was established in other studies. Reliabilities have been found to range from .73 to .83 for the three subscales from which items were taken (Kabacoff, Miller, \& Bishop, 1990). For this sample, Cronbach's alpha coefficients are as follows: (a) parent one $(\mathrm{P} 1)=.893$, parent two $(\mathrm{P} 2)=.903$ (overall measure); (b) P1 =.879, $\mathrm{P} 2$ $=.880$ (General Functioning subscale); and (c) P1 =.830 and P2 =.843 (Affective Response subscale; Day et al., 2010). Taken together, the FAD reports the necessary psychometric properties to make valid and reliable inferences regarding family functioning.

Media connection. This scale was used with parents and children to determine how often they used media or technology to connect and communicate with each other. Parents and children responded to a 5-item measure using a 6-point Likert scale ranging from 1 (never) to 6 (more than once a day). Sample items included, "How often do you email your parent/child," "How often do you use social networking sites (such as Facebook) to connect with your parent/child," "How often do you text or call your child on a cell phone," and "How often do you watch TV or movies with your parent/child?" Items were analyzed individually for frequency of use (Day et al., 2010).

Media use. Youth respondents noted how many hours they spend in a typical day using specific media activities including watching TV programs, playing video games, reading books or magazines, and texting on a cell phone. Response categories ranged from 1 (none) to 9 (more than 8 hours; Day et al., 2010). Responses were totaled to estimate total time spent using media.

Parental media monitoring. Parent self-reports were used to assess parental monitoring of children's media exposure using a 7-item measure based on past assessments of child media use (Nikken \& Jansz, 2006; Warren et al., 2002). Participants responded by rating how often they engaged in specific monitoring behaviors using a 5-point Likert scale ranging from 1 
(never) to 5 (very often). Higher scores reflect greater monitoring of children's media exposure and sample items included, "Tell your child to turn off media when you think it is inappropriate," and "Explain reasons why media characters do what they do." For the current sample, Cronbach's alpha reliability coefficients were found to be $.663(\mathrm{P} 1)$ and $.670(\mathrm{P} 2)$.

Youth were also asked to report parental media monitoring using a similar scale. Participants responded to seven items, rating how often their parents engaged in specific monitoring behaviors, using a 5-point Likert scale ranging from 1 (never) to 5 (very often). Higher scores reflect greater perceived monitoring of children's media exposure. Sample items included, "tell you to turn off media when they think it is inappropriate," "try to help you understand what you see in the media" and, "explain reasons why media characters do what they do." For the current sample, the reliability coefficient (Cronbach's alpha) for the entire scale was .820.

Demographic and other variables of interest. The following variables (a) family conflict, (b) depression, and (c) anxiety have been shown to significantly contribute to family functioning. The analysis included these variables so as to more specifically partition variance among the variables. Demographic information such as income, race, age, marital status, and gender were also included.

\section{Analysis}

Data were analyzed using the Statistical Package for Social Sciences (SPSS) Version 18.0 computer software and R version 11.1 (R Development Core Team, 2010). The lme4 library was loaded in $\mathrm{R}$ so the lmer( ) function could be used to analyze the linear mixed effects models (Pinheiro \& Bates, 1996). 
First, basic descriptive statistics of the demographic data were calculated in SPSS, including the mean and median values of the dependent and independent variables. Because the data were nested in families, we employed a mixed model to account for both individual and family variance. Researchers have noted the need for models that account for family-level variance (Poff et al., 2010). Family functioning was the dependent variable. Independent variables of particular interest were parental media monitoring and media connection. The model included other independent variables such as family conflict, depression, anxiety, and demographics in addition to the key media independent variables. This allowed us to more specifically partition out the variance explained by each variable and determine the nature of the relationship between those variables and family functioning. We also created a variable to represent time. We chronologically assigned values (1 and 2) to each wave of data, 1 representing wave 3 of the FFP, and 2 representing wave 4 of the FFP. The wave variable was used in the mixed model to assess the contribution of time to the explanation of variance in family functioning and included it in the model. Statistical significance was assessed using the likelihood ratio test paradigm as implemented in R ( $\mathrm{R}$ Development Core Team, 2010).

The relationship of one additional independent variable to the outcome variable of family functioning was analyzed separately. The relationship between media use and family functioning did not require mixed model because the data only existed for youth. The relationship between media use and family functioning, however, was of particular interest to this study, and therefore was included in the analysis. The relationship as analyzed using a linear regression model that accounted for the other independent and demographic variables. These linear regression models were developed using SPSS. 


\section{Findings}

The following descriptive statistics were calculated for parent one, parent two, and child at waves three and four: (a) family functioning, (b) media connection, and (c) parental media monitoring. Scores for these scales for both waves fell within normal parameters (see Table 1). Descriptive statistics were calculated for media use among child respondents at waves three and four. Scores for these scales fell within normal parameters (see Table 2).

\section{Multiple Regression Analysis}

Because media use data were only collected from child respondents, a multiple regression model was used to ascertain the relationship between media use and family functioning from a youth perspective. In the first regression analysis, family functioning was regressed on the independent variables of ethnicity, family conflict, depression, and anxiety. This block explained a significant amount of variance $\left(R^{2}=.303, p<.001\right)$. In the second block, when the media use, media connection, and parental media monitoring variables were added, there was a significant change in the variance explained by the model $\left(\Delta R^{2}=.043 . p<.001\right)$, and media use became a significant predictor of family functioning from a youth perspective $(B=-.065, p=$ $.010)$. Media connection $(B=.264, p<.001)$, and parental media monitoring $(B=.113, p=.005)$ were also significant predictors of family functioning (see Table 3).

\section{Mixed Model}

The relationship between parental media monitoring, media connection, and family functioning was assessed using a mixed model which appropriately accounted for the multiple sources of variance inherent in this data: individual-level variance, and family-level variance. The Intraclass Correlation Coefficient (ICC) (the ratio of between vs. total variation) was approximately $34.9 \%[7.30 / 20.94=\operatorname{var}($ family $) /(\operatorname{var}($ family $)+\operatorname{var}($ error $))]$ and represents shared 
variance in the ratings of family, or in other words, how strongly individuals in the same family resemble each other. When accounting for the variance explained by gender, age, depression, anxiety, and family conflict, the restricted maximum likelihood mixed model indicated parental media monitoring was a significant predictor of family functioning $\left(t=7.10, t_{\text {crit }}=1.96, d f=\right.$ 470); there was a positive relationship between parental media monitoring and family functioning $(\beta=0.129)$. Media connection was also a significant predictor of family functioning $\left(t=2.16, t_{c r i t}=1.96, d f=470\right)$; the relationship between media connection and family functioning was positive $(\beta=0.063)$.

A second model was developed to assess any interaction effects between the independent variables in estimating family functioning. With interaction effects, the second model's ICC was also approximately $34.9 \%[7.26 / 20.80=\operatorname{var}($ family $) /(\operatorname{var}($ family $)+\operatorname{var}($ error $))]$. The interaction between gender and age was the only statistically significant predictor of family functioning $(t=$ $\left.-3.121, t_{\text {crit }}=1.96, d f=470, \beta=-.032\right)$.

A third model estimated family functioning using the independent variables of wave (representing the time element), gender, age, depression, anxiety, family conflict, media connection, parental media monitoring, and the gender-age interaction. This model reported an ICC of 35\% [7.30/20.87 = var(family $) /(\operatorname{var}($ family $)+\operatorname{var}($ error $))]$. The restricted maximum likelihood mixed model indicated parental media monitoring was a positive and significant predictor of family functioning $\left(t=7.29, t_{c r i t}=1.96, d f=470, \beta=0.132\right)$. Media connection was also a significant positive predictor of family functioning $\left(t=2.11, t_{\text {crit }}=1.96, d f=470, \beta=\right.$ 0.061) (see Table 4). The gender-age interaction was also significant $\left(t=-3.46, t_{\text {crit }}=1.96, d f=\right.$ $470, \beta=-0.03)$. Wave was not a significant variable in the model. 


\section{Discussion}

The intent of this study was to examine the relationship between media as family leisure and family functioning among families with at least one adolescent child. Specifically, this study examined the relationship between family functioning and media use, media connection, and parental media monitoring from a nested data approach. Furthermore, because the data were nested in families, and because most family leisure research has been limited to individual-level analyses, this study incorporated a mixed model which accounted for family-level and individual-level variance in the data analysis. There were several key findings from this study. First, media use and youth perceptions of family functioning were negatively associated, and this finding was statistically significant. Second, media connection and family functioning were significantly positively related, and that relationship was stable across time. Finally, parental media monitoring and family functioning were significantly positively related, and the relationship was stable across time.

\section{Media Use and Family Functioning}

Consistent with other media effects research, the linear regression model indicated the relationship between media use and family functioning was statistically small to moderate. When interpreted in context of the vastness of the mass media audience, however, these small to moderate effects become meaningful. This finding corroborated our initial hypothesis that media use would negatively correlate with family functioning. We anticipated a negative relationship because researchers call media use such as TV viewing an increasingly solitary activity that when engaged in as a family creates a passive experience, and is associated with a decrease in family conversations (Bovill \& Livingstone, 2001; Brock, 2007; Daly, 1996; Dempsey, 2005; Kubey, 1990). 
A significant negative relationship between media use and family functioning from a youth perspective was shown in the second block of the blocked linear regression model. Interestingly, this relationship was revealed only after adjusting for demographic variables, depression, family conflict, anxiety, parental media monitoring, and media connection. Depression, family conflict, and anxiety were all negatively correlated to family functioning. In contrast there was a significant, positive relationship between media connection, parental media monitoring, and family functioning. After accounting for the positive relationships (between media connection, parental media monitoring, and family functioning) the negative relationship between media use and family functioning was revealed. These findings indicate higher levels of youth media use are associated with statistically significant lower levels of family functioning. In other words, youth who use high levels of media are less likely to report high levels of family functioning — suggesting youth media use separate from family media use (i.e., media connection) does not facilitate interaction or communication, a critical component of family functioning.

This finding is an important indicator of the nature of the relationship between media use and family functioning. This particular relationship between media use and family functioning has been assessed on a limited basis. Youth media use has been analyzed in context of physical health, time children spend with parents, family violence, psychological well-being, learning processes, aggressive behaviors, youth adjustment, and youth identity development, but has not been addressed in relationship with a direct measure family functioning (Anderson et al., 2003; Christakis et al., 2004; Dworak, Schierl, \& Struder, 2007; Hawks, 1991; Mesch, 2006; Neuman, 1986; as cited in Perse, 2001; Robinson \& Godbey, 1999; Shaw, Kleiber, \& Caldwell, 1995; Tucker \& Friedman, 1989). Overall family functioning in context of media needs to be 
addressed because media use is the most engaged in form of leisure and entertainment, and leisure has the potential to influence family and individual well-being (Agate et al., 2009; Brock, 2007; Mactavish \& Schleien, 2004; Orthner \& Mancini, 1990; Poff, et al., 2010; Robinson, 1969; Zabriskie \& McCormick, 2001). Therefore, this study adds to the existing leisure and media effects literature by identifying the nature of the relationship between media use and family functioning in this sample.

This study also provides empirical evidence that the overall relationship of youth media use is negatively associated with family functioning levels, even when adjusting for media connection and parental media monitoring. In context of leisure research, this suggests the way in which media is used (i.e., jointly or individually) may be an important factor in understanding the relationship between media and family. Because parental media monitoring was also positively related to family functioning in the multiple regression model, this study suggests the way in which a parent monitors, engages in behavior control, and communicates with a child about media is crucial to understanding the overall relationship between media and family functioning. In context of family leisure research, this relationship may reflect the concept of parents socializing children through leisure. Still, as evidenced in existing literature, media use and its effects remain unclear; the nature of the relationship is both positive (as illustrated by the relationship between media connection and parental media monitoring) and negative (as illustrated by the relationship between media use and family functioning from a youth perspective).

\section{Media Connection and Family Functioning}

The relationship between media connection and family functioning was assessed using a mixed model. Because the data used in this analysis were nested in families, a model that did not 
account for the multiple sources of variability would be inappropriate. In assessing this model, the relationship between media connection and family functioning was determined to be statistically significant and positive. This finding confirmed our initial hypothesis that media connection would positively correlate with family functioning for families with at least one child. This conclusion was indicated by the significance of the variance explained by media connection in the mixed model which accounted for both family-level and individual-level variance of gender, age, depression, anxiety, family conflict, the gender-age interaction, and parental media monitoring. Furthermore, this trend was stable across time; the positive relationship remained consistent and significant between waves three and four of data collection. The stability of the relationship between media connection and family functioning across time suggests that despite a constantly changing media landscape, joint family media use and mediated family communication (i.e., media connection) may continue to be an important consideration in understanding family functioning in context of media-based family leisure.

Media connection was defined as the ways in which parents and children use media or technology to connect with each other, including communicating through media or technology, or using media or technology conjointly (Day et al., 2010). The media connection instrument included items such as "How often do you play video games with your child/parent," "How often do you use social networking sites (such as Facebook) to connect with your child/parent," "How often do you email your child/parent," and "How often do you watch TV or movies with your child/parent" (Day et al.). The media connection variable questions were separate from other items in the FFP that asked parents, for example, "how many hours a day do you spend on the internet (work)?" thereby specifying a difference between leisure and work-related media use (Day et al.) Furthermore, existing research has established the activities listed in the media 
connection variable as leisure activities. For example, television is commonly referenced as a home-based leisure activity that has been associated with family functioning, identity development, and adjusting family leisure in the case of severe illness (Radina, 2009; Shaw et al., 1995; Zabriskie \& McCormick, 2001).

Existing research also suggests communication is an inherent element of family leisure (Wells, Widmer, \& McCoy 2004; Zabriskie \& McCormick, 2001). Mediated communication such as texting has been shown to increase a sense of connectedness by allowing family members to communicate in environments and situations that did not allow voice communication (Pettigrew, 2009). Furthermore, shared leisure such as watching television shows together can become a ritualized family activity (Silverstone, 1993). Additionally, Internet use has been shown to provide increased opportunities for family interaction, communication, and collaboration, thereby potentially influencing family functioning (Mesch, 2006). Finally, daughters who play age-appropriate video games with their fathers report stronger mental health, a stronger sense of family connectedness, and exhibit better behavior (Coyne et al., 2011).

Consistent with those findings, this study demonstrated a positive relationship between media connection and positive family outcomes, namely higher levels of family functioning. In context of the McMaster Model of Family Functioning, the degree to which the family exhibits "interest in and values the activities and interests of individual family members," known as affective involvement is a key measure of family functioning (Miller et al., 2000, p. 171). Thus, when considered as affective involvement, these findings suggest media connection (the degree to which family members share media-based leisure) should indeed be associated with higher levels of family functioning. 
Overall, findings clearly indicated families in this sample who shared media-based activities and used media as a communication tool were more likely to consistently report stronger communication, better problem-solving abilities, a higher level of emotional involvement, and subsequently, higher overall family functioning.

\section{Parental Media Monitoring and Family Functioning}

The final key finding from this study was the positive relationship between parental media monitoring and family functioning. This finding confirmed our initial hypothesis that parental media monitoring would be positively related to family functioning. Of particular importance was the size of the relationship between parental media monitoring and family functioning (see Table 4). Even after adjusting for gender, age, depression, anxiety, family conflict, the gender-age interaction, and media connection, parental media monitoring was still statistically significant. Furthermore, the strength of the relationship remained stable and consistent across time.

Existing literature has indicated parent-child communication about media can provide a certain level of protection and even deterrence from delinquent child behavior, and can block negative viewing effects (Kennedy et al., 2007; Warren et al., 2002). In this study, parental media monitoring was defined as how often parents engaged in specific monitoring behaviors to regulate their children's exposure to media (Day et al., 2010). For example, parent and child respondents were asked to report how often they discussed why some things media characters do are good or bad, reasons why media characters do what they do, and tried to help the child understand what he or she saw in the media (Day et al.). As stated earlier, communication is a key construct of family functioning (Miller et al., 2000). Therefore, parents and children who 
communicate more about the media they use are expected to report higher levels of family functioning.

Behavior control, another key component of family functioning, is the manner in which a family addresses physically dangerous situations, psychological needs, and interpersonal socializing behavior (Miller et al., 2000). Socialization "refers to the way in which individuals are assisted in becoming members of one or more social groups" (Grusec \& Hastings, 2007, p. 1). While the measure of parental media monitoring in the current study is not a leisure-specific measure, it does offer potentially important insight into socialization via family leisure. Kleiber (1999) stated parents "often take advantage of leisure opportunities and activities to teach children important skills and values" (p. 66). In terms of media, research indicates parents socialize their children to their media attitudes, beliefs, practices, and habits (Neuman, 1986). Neuman analyzed the home learning environment in terms of children's TV viewing habits and leisure reading preferences. She surveyed fifth graders to determine their home media habits in degrees of television viewing and reading. According to combined categories of viewing and reading, as well as the results of the home environmental questionnaire administered to parents, there was a significant relationship between media behavior and certain family patterns (Neuman). Similarly, the parents in the current study who employed media monitoring to mediated-family leisure behaviors were likely to have engaged in similar socialization processes possibly facilitating the reported positive family outcomes.

Parental media monitoring also included limiting the amount of media a child watched, telling a child to turn off inappropriate media, and forbidding certain types of media. These media monitoring habits are analogous to not only leisure-based socialization but also the behavior control component assessment of family functioning based on the McMaster Model. 
Thus, it would appear according to this study that moderating negative viewing effects and engaging in behavior control via parental media monitoring is associated with higher levels of family functioning. The size and stability of the relationship between parental media monitoring and family functioning suggests the degree to which parents regulate their children's media habits is perhaps the single most important media-related factor associated with family functioning.

\section{Practical Implications}

Findings from this study have valuable implications for families, practitioners, and family leisure and media effects scholars. This study provided empirical evidence that certain types of media-based leisure activities and behaviors are associated with higher levels of family functioning, while others are associated with lower levels of family functioning. In general, these mixed results are consistent with media effects research. Additionally, findings suggest the way in which families use media is an important consideration when analyzing the relationship between media use and family functioning.

Findings, however, go beyond much of the existing family leisure and media effects research because the statistical analysis accounted for family level variance when estimating family functioning. Family leisure and media effects researchers have called for research that accounts for group or macro-level variance in addition to individual or micro-level variance. Perse (2001) argued a focus on individual-level effects in media effects research was obscuring larger, societal level effects. Furthermore, media effects on families as a whole have been examined only on a limited basis, and this study demonstrates mixed models can be effectively employed to ascertain and explain the variance of family functioning at a group-level. Poff et al. (2010) has also noted the lack of family leisure research that accounts for family-level variance, 
and has called for studies that incorporate such multilevel methods. By accounting for family level variance, the model in this study begins to fill the gap in both disciplines.

In addition to going beyond existing statistical methods, this study also analyzed the relationship between media connection and parental media monitoring over time. By incorporating two different waves of data collected a year apart, this model illustrates the stability of the relationship between media connection, parental media monitoring, and family functioning. This suggests to family leisure and media effects researchers the importance of longitudinal studies in understanding the relationship between media variables and family outcomes. Stability across time indicates higher levels of parental media monitoring and media connection are expected to be consistently related to better problem-solving abilities, higher levels of emotional involvement, improved behavior control, and therefore, higher levels of overall family functioning among families with at least one adolescent child.

In terms of systems theory, and the McMaster Model of Family Functioning, these results offer some insight into practical application of the constructs of communication, affective involvement, and behavior control. Findings from this study suggest some media behaviors (i.e., using media conjointly between parent and child, communicating using media, and parental monitoring of media use) are associated with higher levels of family functioning, which is particularly important since media represents the most popular form of leisure and entertainment in America today (Brock, 2007; Robinson, 1969).

According to current findings, using media such as cell phones, texting, and social networks as communication channels between parents and children is associated with higher family functioning. Moreover, parents and youth who engage in media use together (i.e., affective involvement), are more likely to report higher levels of family functioning, and 
therefore similar media-based family leisure behaviors should be encouraged. Furthermore, parents who involve themselves in the types of media their children use and monitor their media behaviors and activities, are also more likely to report higher family functioning. This knowledge may aid parents as well as family therapists. Family therapists could discuss ways in which adolescents and parents use media to connect with each other. For example, a parent could use text to let his or her child know that they love and care for them, even when they are away from the home. Parents who are concerned that their children are playing too many video games or watching too much TV could engage in these activities with their children. Therapists might advise parents to discuss some of the themes and behaviors that occur in these games and programs. Such discussion may provide a starting point for serious discussion about relationships, peers, problem behaviors, or more.

\section{Limitations and Recommendations for Future Research}

Overall, findings from this study indicated a negative relationship between media use and family functioning from a youth perspective, and conversely, a positive relationship between media connection and parental media monitoring, and family functioning. Limitations, however, must be recognized. First, because the sample was limited to families with adolescent children between the ages of 11 and 16, generalizability is limited to families with similar structures. Future research should consider examining the nature of media use in relation to family functioning at various life stages and child respondent ages (Davies \& Gentile, 2011).

Second, because the data relied on memory recall in an uncontrolled setting, the media use measurement may have been imprecise and subject to considerable random error (Perse, 2001). Future research should consider incorporating other measurement techniques such as time diaries to more accurately estimate media use. 
Third, though the sample accurately modeled ethnicity distribution in the United States in most cases, Hispanic families were underrepresented in this sample. Furthermore, the sample was geographically exclusive to a large northwestern city, and some families were not selected randomly, rather by referral. Considering these limitations, generalizability may be limited. Future research should incorporate random sampling techniques, a more ethnically representative sample, and expand the sample to include families with children in other life stages.

Fourth, though this study found a positive relationship between media connection and positive family outcomes, namely higher levels of family functioning, whether this relationship can be wholly attributed to the established benefits of family leisure remains unclear. Future research should focus on the benefits specifically associated with media-based family leisure by incorporating more specific family leisure measures. Similarly, the parental media monitoring scale used in this study was not specific to leisure-behaviors. Therefore, these findings may not be wholly attributable to the benefits of family leisure. Future research should again, hone in on family-leisure focused media monitoring to further ascertain the nature of the relationship between parental media monitoring and family outcomes.

Despite this and other empirical evidence suggesting parental media monitoring is positively related to family functioning, media monitoring practices are not employed by all parents (Warren et al., 2002). This suggests a need for more application of research. It also indicates a need to evaluate media-based leisure activities and behaviors both at the individual and family levels.

Based on current findings, it is recommended family leisure and media effects scholars dedicate more resources to examining and understanding the relationship between media as leisure and family functioning. Ever-changing technologies that make media more accessible 
and the corresponding increase in use will continue to impact media behaviors, attitudes, and family leisure habits and practices. Family leisure scholars must begin to include media-based leisure in their research as media is one of the fastest growing, and most popular forms of entertainment and leisure and merits more attention (Brock, 2007; Rideout et al., 2010; Roy, 2009; Ryan et al., 2006). Furthermore, future research should analyze the relationship between media connection and family outcomes by individual media types. Additionally, the relationship between parental media monitoring and family outcomes should be assessed by the subtypes of parental media monitoring: restrictive and instructive, or active monitoring. Overall, it is clear that media will continue to play an increasingly significant role in understanding the evolution of today's families and therefore, family leisure scholars and parents alike cannot afford to overlook the impact of media-based family leisure. 


\section{References}

Agate, J. R., Zabriskie, R. B., Agate, S. T., \& Poff, R. (2009). Family leisure satisfaction and satisfaction with family life. Journal of Leisure Research, 41(2), 205-223.

Ahlstrom, M., Lundberg, N. R., Zabriskie, R., Eggett, D., \& Lindsay, G. B. (2009). Me, my wife, and my Avatar: The relationship between marital satisfaction and playing massively multiplayer online role-playing games (MMORPGs). Unpublished manuscript, Department of Recreation Management Youth Leadership, Brigham Young University, Provo, Utah, United States.

Bovill, M., \& Livingstone, S. M. (2001). Bedroom culture and the privatization of media use. London, England: LSE Research Online.

Brock, B. (2002). Life without TV: Filling those four hours with more satisfying leisure. Parks and Recreation, 37(11), 68-73.

Brock, B. (2007). Living outside the box: TV-free families share their secrets. Spokane: Eastern Washington University Press.

Caroli, M., Argentieri, L., Cardone, M., \& Masi, A. (2004). Role of television in childhood obesity prevention. International Journal of Obesity, 28, S104-S108.

Christakis, D., Zimmerman, F. J., DiGiuseppe, D. L., \& McCarty, C. A. (2004). Early television exposure and subsequent attentional problems in children. Pediatrics, 113(4), 708.

Coffin, T. E. (1948). Television's effects on leisure-time activities. Journal of Applied Psychology, 32(5), 550-558.

Coyne, S. M., Meng, N., Harper, J., Nelson, D. A., \& Keister, E. (2008). TV violence and abuse in romantic relationships: The importance of relational aggression. Poster presented at 
the International Society for the Study of Behavioural Development XX World Meeting, Wurzburg, Germany.

Csikszentmihalyi, M., \& Kubey, R. (1981). Television and the rest of life: A systematic comparison of subjective experience. Public Opinion Quarterly, 45(3), 317.

Daly, K. (1996). Families \& time: Keeping pace in a hurried culture. Thousand Oaks, CA: Sage.

Davies, J., \& Gentile, D. (2011). Media uses and effects in stages of family life: A family development perspective. Paper accepted for presentation in the Virtual Session of the International Communication Association conference, Boston, MA: May 26-30, 2011.

Day, R. D., Bean, R., Harper, J., Miller, R., Walker, L., Yorgason, J., \& Coyne, S. (2010). Codebook - wave III (7-15-10): Greater Seattle area. Flourishing Families Project: Survey of Family Life.

Dempsey, N. P. (2005). Television use and communication within families of adolescents. In B. Schneider \& L. Waite (Eds.), Being together, working apart (pp 277-296). New York, NY: Cambridge.

Dworak, M., Schierl, T., Bruns, ,T., \& Struder, H. K. (2007). Impact of singular excessive computer game and television exposure on sleep patterns and memory performance of school-aged children. Pediatrics, 120(5), 978-985.

Epstein, N. B., Baldwin, L. M., \& Bishop, D. S. (1983). The McMaster family assessment device. Journal of Marital and Family Therapy, 9, 171-180.

Ghali, M. N. (2009). Attachment to parents, family communication patterns, and family satisfaction in emerging adulthood (Doctoral dissertation). Retrieved from http://proquest.umi.com/pqdlink?Ver=1\&Exp=12-062015\&FMT=7\&DID=1918566981\&RQT=309\&attempt=1. 
Grimm, J. (2008). Physical effects of media content. In W. Donsbach (Ed.), The international encyclopedia of communication. Retrieved from http://www.communicationencyclopedia.com/subscriber/tocnode?id=g9781405131995_c hunk_g978140513199521_ss36-1

Grusec, J. E., \& Hastings, P. D. (2007). The handbook of socialization: Theory and research. New York, NY: The Guilford Press.

Hawks, S. R. (1991). Recreation in the family. In S.J. Bahr (Ed.), Family research: A sixty-year review, 1930-1990, Vol. 1, (387-433). New York: Lexington books.

Internet World Stats. (2010, January 6). Internet usage and population in North America. Retrieved from http://www.internetworldstats.com/stats14.htm

Jeffres, L. W., Neuendorf, K., \& Atkin, D. (2003). Media use and participation as a spectator in public leisure activities: Competition or symbiosis? Leisure Studies, 22(2), 169-184.

Kabacoff, R. I., Miller, I. W., \& Bishop, D. S. (1990). A psychometric study of the McMaster Family Assessment Device in psychiatric, medical, and nonclinical samples. Journal of Family Psychology, 3(4), 431-439.

Kennedy, C., Chen, J. L., \& Charlesworth, A. (2007). Maternal health, family functioning and family media practices. Annals of Behavioral Medicine, 33(S1), S117.

Kepplinger, H. M. (2008). Media effects. In W. Donsbach (Ed.), The international encyclopedia of communcation. Retrieved from http://www.communicationencyclopedia.com/subscriber/tocnode?id=g9781405131995_c hunk_g978140513199518_ss29-1

Kleiber, D. (1999). Leisure experience and human development: A dialectical interpretation. New York, NY: Basic Books. 
Kim, H., Kim. G. J., Park, H. W., \& Rice, R. E. (2007). Configurations of relationships in different media: FtF, email, instant messenger, mobile phone, and SMS. Journal of Computer-Mediated Communication, 12(4), 1183-1207.

Kubey, R. (1990). Television and the quality of family life. Communication Quarterly, 38(4), 312-324.

Larson, R., Kubey, R., \& Colletti, J. (1989). Changing channels: Early adolescent media choices and shifting investments in family and friends. Journal of Youth and Adolescence, 18(6), 583-599.

Mactavish, J. B., \& Schleien, S. J. (2004). Re-injecting spontaneity and balance in family life: Parents' perspectives on recreation in families that include children with developmental disability. Journal of Intellectual Disability Research, 48(2), 123-141.

Mesch, G. S. (2006). Family relations and the Internet: Exploring a family boundaries approach. The Journal of Family Communication, 6(2), 119-138.

Miller, I. W., Ryan, C. E., Keitner, G. I., Bishop, D. S., \&, Epstein, N. B. (2000). The McMaster approach to families: Theory, assessment, treatment and research. Journal of Family Therapy, 22, 168-189.

Neuman, S. (1986). Television, reading, and the home environment. Literacy Research and Instruction, 25(3), 173-183.

Nikken, P., \& Jansz, J. (2006). Parental mediation of children's videogame playing: A comparison of the reports by parents and children. Learning, Media, and Technology, 31, $181-202$ 
Nutter, J. A., Zabriskie, R. B., Hill, B. J., \& Eggett, D. L. (2008). Contributions of family leisure to family functioning among families with an adolescent in mental health treatment. Unpublished manuscript.

Orthner, D. K., \& Mancini, J. A. (1990). Leisure impacts on family interaction and cohesion. Journal of Leisure Research, 22(1), 125-137.

Orthner, D. K., \& Mancini, J. A. (1991). Benefits of leisure for family bonding. In B. L. Driver, P. J. Brown, \& G. L. Peterson (Eds.), Benefits of Leisure (pp. 215-247). State College, PA: Venture.

Perse, E. M. (2001). Media effects and society. Mahwah, NJ: Lawrence Erlbaum Associates. Pettigrew, J. (2009). Text messaging and connectedness within close interpersonal relationships. Marriage \& Family Review, 45(6), 697-716.

Pinhiero, J. C., \& Bates, D. M. (1996). Unconstrained parameterizations for variance-covariance matrices. Statistics and Computing, 6, 289-295.

Poff, R., Zabriskie, R., \& Townsend, J. (2010). Modeling family leisure and family related constructs: A national study of U.S. parent and youth perspectives. Journal of Leisure Research, 42(3), 365-391.

R Development Core Team. (2010). R: A language and environment for statistical computing. R Foundation for Statistical Computing. Vienna, Austria.

Radina, M. E. (2009). Breast cancer-related lymphedema: Implications for family leisure participation. Family Relations, 58(4), 445-459.

Rideout, V. J., Foehr, U. G., \& Roberts, D. F. (2010). Generation $M^{2}$ :Media in the lives of 8- to 18-years olds. Retrieved from Kaiser Family Foundation website http://www.kff.org/entmedia/7251.cfm. 
Roberts, D. F., \& Foehr, U. G. (2008). Trends in media use. The Future of Children, 18(1), 11-37.

Robinson, J. (1969). Television and leisure time: Yesterday, today, and (maybe) tomorrow. Public Opinion Quarterly, 33, 210-222.

Robinson, J., \& Godbey, G. (1999). Time for life: The surprising ways Americans use their time. University Park: Pennsylvania State University Press.

Roy, S. J. (2009). Internet uses and gratifications: A survey in the Indian context. Computers in Human Behavior, 25, 878-886.

Ryan, R. M., Rigby, C. S., \& Przybylski, A. (2006). The motivational pull of video games: A self-determination theory approach. Motivational Emotion, 30, 347-363.

Shaw, S. M., Kleiber, D. A., \& Caldwell, L. L. (1995). Leisure and identity formation in male and female adolescence: A preliminary examination. Journal of Leisure Research, 27(3), 245-263.

Silverstone, R. (1993). Time, information and communication technologies and the household. Time \& Society, 2(3), 283.

Stanton, F. (1949). Television and people. Education, 70(4), 217-224.

The Nielsen Company. (2010). Television, Internet, and mobile usage in the US. Three Screen Report, 8, 1-8.

Tucker, L., \& Friedman, G. (1989). Television viewing and obesity in adult males. American Journal of Public Health, 79(4), 516.

Vandelanotte, C., Sugiyama, T., Gardiner, P., \& Owen, N. (2009). Associations of leisure-time Internet and computer use with overweight and obesity, physical activity and sedentary behaviors: Cross-sectional study. Journal of Medical Internet Research, 11(3), 1-8. 
Warren, R., Gerke, P., \& Kelly, M. A. (2002). Is there enough time on the clock? Parental involvement and mediation of children's television viewing. Journal of Broadcasting \& Electronic Media, 46, 87-111.

Wells, M. S., Widmer, M. A., \& McCoy, K. (2004). Grubs and grasshoppers: Challenge-based recreation and the collective efficacy of families with at-risk youth. Family Relations, 53(3), 326-333.

White, J. M., \& Klein, D. M. (2008). Family theories. Los Angeles, CA: Sage.

Zabriskie, R. B., \& McCormick, B. P. (2001). The influences of family leisure patterns on perceptions of family functioning. Family Relations, 50, 281-289. 
FAMILY MEDIA

\section{Tables}

Table 1 - Means and Standard Deviations

\begin{tabular}{lllc}
\hline Variable & Respondent & Mean & Std. Dev. \\
\hline Family Functioning - Wave 3 & Parent 1 & 39.70 & 5.15 \\
& Parent 2 & 39.28 & 4.75 \\
& Child & 37.55 & 5.55 \\
Media Connection - Wave 3 & Parent 1 & 13.19 & 3.21 \\
& Parent 2 & 12.48 & 3.14 \\
& Child & 12.95 & 3.68 \\
Parental Media Monitoring - & Parent 1 & & \\
Wave 3 & Parent 2 & 24.46 & 4.49 \\
& Child & 22.99 & 4.45 \\
Family Functioning - Wave 4 & Parent 1 & 18.80 & 6.15 \\
& Parent 2 & 39.52 & 5.08 \\
& Child & 39.24 & 5.43 \\
& & 37.29 & 5.68 \\
Media Connection - Wave 4 & Parent 1 & & \\
& Parent 2 & 13.62 & 3.14 \\
Parental Media Monitoring - & Child & 12.96 & 3.24 \\
& & 13.61 & 3.62 \\
\hline & Parent 1 & & \\
& Parent 2 & 23.47 & 4.34 \\
& Child & 22.15 & 4.20 \\
\hline
\end{tabular}


FAMILY MEDIA

Table 2 - Media Use Waves 3 and 4

\begin{tabular}{lcc}
\hline Variable & Mean & Std. Dev. \\
& & \\
\hline Media Use - Wave 3 & 28.88 & 9.76 \\
Media Use - Wave 4 & 31.97 & 10.29 \\
\hline
\end{tabular}


FAMILY MEDIA

Table 3 - Multiple Regression Media Use

\begin{tabular}{lcc}
\hline Predictor & \multicolumn{2}{c}{ Family Functioning } \\
& Std. B & $\beta$ \\
\hline Block 1 R & \multicolumn{2}{c}{$.303^{* *}$} \\
AsianAm & \multicolumn{3}{c}{} \\
Family Conflict & 5.837 & $.098^{*}$ \\
Depression & -.174 & $-.338^{* *}$ \\
& -.178 & $-.315^{* *}$ \\
Block 2 $\Delta \mathrm{R}^{2}$ & \multicolumn{2}{c}{$.043^{* *}$} \\
AsianAm & \multicolumn{2}{|}{} \\
Family Conflict & 5.20 & $.088^{*}$ \\
Depression & -.179 & $-.348^{* *}$ \\
Media Use & -.156 & $-.275^{* *}$ \\
Media Connection & -.065 & $-.117^{*}$ \\
Parental Media Monitoring & .264 & $.168^{* *}$ \\
\hline
\end{tabular}

Note. ${ }^{*} p<.05 ; * * p<.01 ; \mathrm{n}=429$. 
Table 4 - Mixed Model Media Connection and Parental Media Monitoring

\begin{tabular}{lccc}
\hline Variable & Estimate Std. & Error & t value \\
\hline (Intercept) & & & \\
Wave & 43.91 & 1.12 & 39.38 \\
Gender & -0.08 & 0.15 & -.049 \\
Age & 1.98 & 0.42 & 4.76 \\
Depression & 0.02 & 0.02 & 1.35 \\
Anxiety & -0.16 & 0.01 & -10.96 \\
Conflict & -0.11 & 0.03 & -3.39 \\
Media Connection & -0.13 & 0.01 & -14.22 \\
Parental Media Monitoring & 0.06 & 0.03 & 2.11 \\
Gender-age Interaction & 0.13 & 0.02 & 7.29 \\
\hline
\end{tabular}

$t$-crit $=1.96, d f=470$ 
FAMILY MEDIA

Appendix A

Prospectus 


\section{Chapter 1}

Family leisure research has garnered increased attention over the last decade and has focused on how leisure is related to family health and well-being, family functioning, and family life satisfaction (Agate, Zabriskie, Agate, \& Poff, 2009; Mactavish \& Schleien, 2004; Orthner \& Mancini, 1990; Poff, Zabriskie, \& Townsend, 2010; Zabriskie \& McCormick, 2001). Findings consistently indicate family leisure is positively related to cohesiveness, overall satisfaction with quality of family life, healthy couple relationships, healthy relationships between parents and their children, and family strength—all of which contribute to family functioning (Mactavish \& Schleien; Orthner \& Mancini; Poff et al.; Zabriskie \& McCormick). Family leisure clearly plays a key role in the quality of and satisfaction with family life.

Media use is one of the most common leisure pursuits for youth and adults. Young people between the ages of 8 and 18 consume more than 7.5 hours of media each day, (Rideout, Foehr, \& Roberts, 2010). Of media use, television (TV) is one of the most prevalent leisure pastimes. More than one-half of all Americans claim TV is their primary form of entertainment (Brock, 2002). The Nielsen Company (2010), a leading media research group, reported Americans watch more than 35 hours of TV per week. Contributing to overall viewing time are new viewing technologies that have expanded the reach of television, making it more accessible. The Nielsen Company (n. d.) has acknowledged this change in the way it measures television viewing by including computers and mobile devices as avenues for television viewing.

Computers and mobile devices are only two examples of emerging media technology used for leisure purposes. Computers— and the Internet access they provide—offer several other recreation options such as video games and online gaming - both of which are on the rise (Roy, 2009; Ryan, Rigby, \& Przybylski, 2006). In addition to increased television ownership and 
viewing, Internet use has increased exponentially since it hit popular culture in 1994

(Montgomery \& Faloutsos, 2001). The number of Web servers grew from two million in 1994 to more than 110 million in 2001, to 2 billion in 2010 (Internet World Stats, 2010; Mongtgomery \& Faloutsos).

Media is also quickly becoming an important facilitator of communication —a key factor in family functioning — between family members as well. Mediated communication includes text messages, e-mails, and Internet instant messaging (Pettigrew, 2009). Texting in particular is an effective communication method that increases family members' sense of connectedness (Pettigrew). E-mail and instant messages are also media that increase communication and connectedness (Pettigrew).

Clearly, trends in media use indicate "the "media has moved in with the family and has become one of its core components" (Daly, 1996, p. 76). Such high rates of media use among adults and youth cannot be and are not without effects. Granted, all media effects may not be negative. In fact, research suggests media use in moderation is not particularly harmful to adults (some research suggests young children should not be exposed to screen time until certain developmental markers are achieved; Brock, 2007; Elkind, 2007). Parental media monitoring can mediate the potential negative effects of media as parents teach their children critical viewing skills (Nikken \& Jansz, 2006; Warren, Gerke, \& Kelly, 2002). Parents sharing certain types of media with their children can also have positive outcomes for their children (Coyne, Padilla-Walker, Stockdale, Day, 2011). Additionally, the use of texts, e-mail, and Internet-based instant messaging may facilitate communication between family members (Pettigrew, 2009). One study also indicates using social networks, cell phones, and text messaging facilitate face-to- 
face interaction rather than replacing it (Jacobsen \& Forste, 2010). Still, the ability of media as leisure to produce positive outcomes such as increased family functioning remains in question. Nash's (as cited in Russell, 1996) estimation of the leisure hierarchy and Csikszentmihalyi's (1990) study of optimal experience beg the question: are all forms of leisure equal? And perhaps more importantly, do all forms of leisure-specifically media use — render the same positive outcomes, particularly increased family functioning? Because research substantiates that leisure contributes to family functioning, and media is one of the most common leisure activities, further studies are needed to understand the relationship between leisure media use patterns and family functioning. Furthermore, because most family leisure research has been limited to individual-level analyses, there is a need to incorporate higher level statistics, such as multi-level modeling, which allow for family-level data analysis.

\section{Statement of the Problem}

The problem of this study is to examine the relationship between media as family leisure and family functioning among families with at least one adolescent child. Specifically, this study will attempt to examine the relationship between family functioning and media use, media connection, and media monitoring. Furthermore, because the data is nested in families, and because most family leisure research has been limited to individual-level analyses, this study will incorporate higher level statistics (multi-level modeling) which will account for family-level variance in the data analysis in addition to accounting for individual-level analysis. This study will attempt to answer the following research questions:

1. What is the nature of the relationship between media use and family functioning? 
2. What is the nature of the relationship between joint media use and family functioning media is used jointly between parent and child when analyzed from a family-level perspective?

3. What influence does parental media monitoring have on family functioning when analyzed from a family-level perspective?

4. Does mediated-communication (i.e., texting, e-mail, etc.) significantly contribute to family functioning when analyzed from a family-level perspective?

\section{Purpose of the Study}

Leisure research has clearly established a positive relationship between leisure and positive outcomes. Specifically, scholars have repeatedly found a positive relationship between family leisure and family functioning. Researchers, however, have largely ignored media use as family leisure even though media use represents a significant proportion of leisure activity. The proposed research will take a step toward filling this gap in leisure research. Furthermore, much of the existing family leisure research has approached the analysis of the relationship between leisure and family functioning from an individual-level perspective only. This research will incorporate multi-level modeling to account for family-level variance in addition to individuallevel variance, thereby increasing the understanding of the nature of the relationship between leisure and family functioning. Moreover, there is a gap in research concerning the effects of media on the family. While media effects research has clearly identified relationships between media and various outcomes such as physical health, psychological and emotional well-being, and attitudes and values, social behavior and public opinion, these have been examined solely on the individual level, focusing on youth and adults separately (Caroli, Argentieri, Cardone, \& Masi, 2004; Grimm, 2008; Kepplinger, 2008; Vandelanotte, Sugiyama, Gardiner, \& Owen, 
2009). The research and analysis in this proposal will examine media effects at a family-level and thus begin to fill this gap as well.

\section{Significance of the Study}

Research has determined a positive correlation exists between family leisure and family functioning (Holman \& Epperson, 1984; Orthner \& Mancini, 1990; Poff et al., 2010).

Furthermore, research has demonstrated a similar positive relationship between family leisure and family cohesion (Orthner \& Mancini, 1991). The nature of the relationship between media as family leisure and family functioning has yet to be clearly defined even though researchers claim mass media have influenced leisure patterns (Robinson, 1969).

Media claims a significant portion of leisure time in the United States for individuals, couples, and families and has become a mainstay of family and youth leisure (Brock, 2002; Daly, 1996; Rideout et al., 2010). In fact, Brock (2007) stated decisively, “TV viewing is America's number one recreational pursuit” (p. 3). Brock (2007) also suggests modern attitudes toward leisure have made television America's preferred recreation activity. Rideout et al. estimated children between the ages of 8 and 18 are exposed to almost 8 hours of media each day. Media has clearly established a stronghold in the home and with the family, and "we need to understand 'family-plus-media"” (Daly, p. 76). And, as Perse (2001) suggested, "anything that consumes so much money... and time...must have some impact on our lives" (p. 4). The extensive presence of media in the home and as part of family life requires some exploration to determine how media is affecting the family.

As evidenced by the almost omnipresence of media in the leisure life of Americans, there is continued need to study media effects in context of the family. Interestingly, despite the clear presence of media in the home and as a leisure activity, there is little research detailing the nature 
of the relationship between media, technology, and the family (Mesch, 2006). Media effects research has focused on the individual, "however, to assume that all media effects are accumulations of individual-level effects" is a "fallacy" (Perse, 2001, p. 18). Focusing exclusively on individual-level media effects can potentially "obscure more subtle societal-level effects" (Perse, p. 18). These societal-level effects include the family. The effects of media on physical, emotional, and psychological outcomes as well as its effects on attitudes and values, emotions, and social behavior have been detailed in various studies on an individual level (Grimm, 2008; Kepplinger, 2008). Media effects on families as a whole have been examined only on a limited basis. For example, Neuman (1986) analyzed the home learning environment in terms of children's TV viewing habits and leisure reading preferences. She determined children adopted and internalized their parents' media habits and attitudes. The relationship between media and specific outcomes such as family functioning, however, has not been explored.

Given the focus of previous research on media effects at an individual level, the purpose of this study is to begin to explore media effects on a societal level in the context of family leisure. The analysis will incorporate mixed models to accommodate various levels of variance in the data that is nested in families. More specifically, it is the intent of this research to examine the relationship between media use and family functioning from a statistical perspective that accounts for family-level differences in hopes of adding to the growing research on strengthening families through leisure. This research will also add to the literature and understanding of media effects because "although most scholars acknowledge that mass media effects can occur, we still don't know the magnitude and inevitability of the effects...we don't know how powerful the media are among the range of other forces in society" (Perse, 2001, p. 
16). Societal forces could potentially mitigate or enhance media effects and understanding media effects could further enable "parents, educators, and public officials [with] other tools to fight negative media effects" (Perse, p. 17). Therefore, it is the intent of this research to identify and categorize the relationship of media effects on the family in context of leisure and from a multi-level model analytical approach.

This proposed study will significantly and uniquely contribute to the existing family leisure and media effects research in two ways. First, there is an overall lack of media-centered leisure research. This is surprising given that media use constitutes the majority of leisure time and behavior in the United States. Second, both family leisure and media effects research has focused mainly on individual-level relationships and effects. The proposed research will incorporate family-level relationships into its analysis by using a statistical process known as multi-level modeling. Multi-level modeling will account for family-level variance in the explanation of the relationship between media connection, parental media monitoring, and family functioning from a leisure perspective.

\section{Delimitations}

The scope of this study is delimited to the following:

1. Four hundred and fifty-nine (single- or two-parent) with at least one child between the ages of 11 and 16.

2. Instrumentation and measurements used by the Flourishing Families Project.

3. Parental and child reports of media monitoring measured using self-reports on a 7-item measure based on past assessments of child media use (Nikken \& Jansz, 2006; Warren et al., 2002). 
4. Media connection as measured using a 5-item measure of how often parents and children used media or technology conjointly or to communicate with each other.

5. The presence of various media devices in children's homes assessed using an instrument created specifically for this study.

6. Operationalized definitions regarding family functioning, media use, media connection, mass media, parental media monitoring, family conflict, physical health, and psychological well-being.

7. Self-reports assessing children's media time using items taken from the measure developed by Coyne, Meng, Harper, Nelson, and Keister (2008).

8. The time frame of the study (Waves 3 and 4 of the Flourishing Families Project).

\section{Limitations}

The results from this investigation will be interpreted considering the following limitations:

1. The proposed research is a secondary analysis meaning data were collected by a third party. Constructs and variables were defined by the original researchers.

2. Data will depend on memory recall and estimation of participants which may bias their responses.

3. Because the sample is limited to families with adolescent children (between the ages of 11 and 16), overall media use may be high. Young people (ages 8 to 18) use media upward of 8 hours per day (Rideout et al., 2010).

4. Measuring media exposure is often imprecise in a natural setting as subject to considerable random error (Perse, 2001). The measurement of media use in this data set may be equally imprecise. 
5. Because the sample is limited to families with adolescent children between the ages of 11 and 16 , generalizability of the results of this research will be limited to similar families.

6. Dimensions of the McMaster Model (upon which the FAD is based) are reportedly correlated and the instrument has been criticized because the scales may not be sufficiently independent (Miller, Ryan, Keitner, Bishop, \& Epstein, 2000).

7. The majority of parents in the sample are of European descent.

8. The Polk Directory national database (used to randomly select families) was generated using telephone, magazine, and Internet subscription reports; so families of lower socioeconomic status were underrepresented. Therefore, in an attempt to more closely mirror the demographics of the local area, a limited number of families were recruited into the study through other (non-random) means.

9. Data collection took place in a major northwestern city, which may impact generalizability of the study's results.

10. According to principal investigators, media connection items may be analyzed individually by item. An overall mean for all questions may be computed but reliability is not good.

\section{Hypotheses}

$\mathrm{H}_{01}$ : Media use will not be correlated to family functioning for families with at least one child.

$\mathrm{H}_{\mathrm{a} 1}$ : Media use will be negatively correlated to family functioning for families with at least one child.

$\mathrm{H}_{02}$ : Media connection will not correlate with family functioning for families with at least one child. 
$\mathrm{H}_{\mathrm{a} 2}$ : Media connection will positively correlate with family functioning for families with at least one child.

$\mathrm{H}_{03}$ : Parental media monitoring will not be correlated to family functioning for families with at least one child.

$\mathrm{H}_{\mathrm{a} 3}$ : Parental media monitoring will positively correlate to family functioning for families with at least one child.

\section{Definition of Terms}

1. Mass Media: Comprised of four characteristics: (a) broad appeal (ability to attract a diverse audience), (b) speed (timeliness of delivery), (c) availability (accessibility across wide geographic span and sensory outlets), and (d) low unit cost (Stanton, 1949).

2. Media Use: Participant-reported number of hours they spend in a typical day using specific media activities including watching TV programs, playing video games, reading books or magazines, texting on cell phone (Day et al., 2010).

3. Media Connection: How parents and children use media or technology to connect with each other, including communicating through media or technology, or using media or technology conjointly (Day et al., 2010).

4. Parental Media Monitoring: Parental self-reports on how often they monitor their children's exposure to media—specifically measuring how often parents engage in specific monitoring behaviors (Day et al., 2010).

5. Family: Two-parent and single-parent families with a child between the age of 11 and 16 (Day et al., 2010).

6. McMaster Family Assessment Device (FAD): Perceptions of family functioning will be measured using 20 items from the McMaster Family Assessment Device (Epstein, 
Baldwin, \& Bishop, 1983). The FAD is based on the McMaster Model, and "was designed to assess the dimensions of the McMaster Model according to family members' perceptions" (Miller et al., 2000, p. 173). The McMaster and FAD are based on systems theory assuming "all parts of the family are interrelated" and "one part of the family cannot be understood in isolation from the rest of the family system" (Miller et al., p. 169).

7. Family Functioning: An assessment and formulation of "six dimensions of family life: problem-solving, communication, roles, affective responsiveness, affective involvement, and behaviour control" (Miller et al., 2000, p. 170). Measured according to the McMaster Model and using the FAD.

8. Family Conflict: Parents and children rate how frequently specific topics cause conflict, including movies and TV (Day et al., 2010).

9. Flourishing Families Project (FFP): an ongoing longitudinal study of inner-family life involving families with a child between the ages of 11 and 16. The general purpose of this project is to show how family processes (measured observationally and from survey questionnaires) impact the social development of young people as they make the transition from grade school, through high school, and into young adulthood (Day et al, 2010).

10. Parent $1(P 1)$ : In most instances, the Parent $1(\mathrm{P} 1)$ designation pertains to the mother or mother figure in the family, because she was "nominated" as the parent supplying the majority of the caregiving. In cases of single-father families and two-parent families where the father is primary caregiver, the father is designated as P1 (Day et al., 2010). 


\section{Chapter 2}

\section{Review of Literature}

The problem of this study is to examine the relationship between media as family leisure and family functioning among families with at least one adolescent child. Specifically, this study will attempt to examine the relationship between family functioning and media use, media connection, and media monitoring. Furthermore, because the data is nested in families, and because most family leisure research has been limited to individual-level analyses, this study will incorporate higher level statistics (multi-level modeling) which will account for family-level variance in the data analysis in addition to accounting for individual-level analysis.

\section{Family Functioning}

Researchers have named some fundamental measurable outcomes in seeking to better understand positive family attributes. One way researchers achieve this is by studying the construct of family functioning. Measuring family functioning is a complex endeavor because it can be assessed in many ways (Epstein, Baldwin, \& Bishop, 1983). For the purposes of this research, family functioning will be assessed in context of the McMaster Model of Family Functioning as part of the systems theory (Day et al., 2010; Miller et al., 2000).

Systems theory. The McMaster Model of Family Functioning is part of systems theory, suggesting "all parts of the system are interconnected" and "understanding is only possible by viewing the whole" (White \& Klein, 2008, p. 156). In context of the family, systems theory suggests families are "greater than just a collection of individuals" because of the way they interact and how those interactions provide feedback (White \& Klein, p. 156). More specifically, the concept of feedback, or the way a system such as a family affects its environment and vice versa, is critically important to full understanding of the system. According to White and Klein, 
family systems theory is useful in understanding marital and family communications and interactions.

The critical components of systems framework include: (a) system, or the relations between a set of objects and their attributes, meaning the system is separate from its environment but has an effect on it; (b) boundaries, which affect the flow of information and energy between the system and its environment; (c) rules of transformation, which is the equivalent of quid pro quo; (d) feedback, or the input and output of the system; (e) variety, or the ability to adapt to a changing environment; (f) equilibrium, or how a system achieves balance between input and output; (g) system levels, the varying degrees of prioritized goals; and (h) subsystems, various levels in a system such as parents and children (White \& Klein, 2008).

McMaster Model of Family Functioning. Assumptions of systems theory are fundamental parts of the McMaster Model of Family Functioning. The McMaster Model of Family Functioning assumes "all parts of the family are interrelated" and parts of the family cannot be understood when separated from the rest of the family system (Miller et al., 2000, p. 169). Furthermore, the McMaster Model of Family Functioning posits family functioning cannot be understood by studying only individual members or subgroups of the family and that the influence of family structure and organization must be accounted for. Finally, the McMaster Model of Family Functioning states the influence of family interaction patterns must also be accounted for in order to understand family functioning (Miller et al.).

In order to meet those assumptions, the McMaster Model focuses on six dimensions of family life to accurately assess family functioning. Therefore the definition of family functioning comprises those six dimensions of "problem-solving, communication, roles, affective responsiveness, affective involvement, and behavior control" (Miller et al., 2000, 
p. 170). Problem-solving measures the ability of the family to resolve conflict and problems in such a way that maintains family functioning. Communication focuses on verbal exchanges in examining how information is shared within a family. Roles are the behavior patterns family members engage in to preserve and fulfill family functions. Affective responsiveness is the emotional ability of families to appropriately respond to stimuli while affective involvement is the degree to which the family exhibits "interest in and values the activities and interests of individual family members" (Miller et al., p. 171). Finally, behavior control is the manner in which a family addresses physically dangerous situations, psychological needs, and interpersonal socializing behavior (Miller et al.).

Family functioning research. Family functioning has been examined in context of physical, mental, and emotional well-being. Researchers have explored and continue to explore the relationship between family functioning and variables such as parental illness, traumatic brain injury, adolescent well-being, schizophrenia, anxiety disorders, mood disorders, posttraumatic stress disorder, division of household labor, depression, and low-income (Evans, Cowlishaw, \& Hopwood, 2009; Hossain, 2001; Hughes, Hedtke, \& Kendall, 2008; McCreary \& Dancy, 2004; Pedersen \& Revenson, 2005; Ponsford \& Schonberger, 2010; Sawant \& Kamal, 2010). Family functioning has also been studied in context of marital status, income, delayed parenthood, and from ethnic and racial perspectives (Garrison, Blalock, Zarki, \& Merritt, 1997; Mandara \& Murray, 2000; Mandara \& Murray, 2002; McCreary \& Dancy). Family functioning has complex relationships with health—specifically mental health. For example, family criticism and family emotional involvement are directly associated with depressive symptoms as well as healthy cardiovascular behaviors (Franks, 1992). Furthermore, psychological well-being 
and physical health significantly contribute to family functioning (Georgiades, Boyle, Jenkins, Sanford, \& Lipman, 2008).

Certain demographic variables have also been shown to significantly contribute to predicting family functioning in research similar to the proposed research. Some of those variables, and those that will be considered in this research, are marital status-specifically single parent households, low socioeconomic status, family size, gender of dependent children, dependent child age, and parental education (Georgiades et al., 2008). All these variables have significance in predicting family functioning when using a multi-level model approach and the McMaster Family Assessment Device—both of which will be used in the proposed research.

Other facets of family functioning specific to this proposal will be reviewed more indepth. These are: (a) conflict and family functioning; (b) family functioning and communication, including technologically mediated communication; (c) leisure and family functioning; and (d) family functioning and media use.

Conflict and family functioning. As outlined in the McMaster Model of Family Functioning, problem solving measures the ability of the family to resolve conflict and problems in such a way that maintains family functioning (Miller et al., 2000). Researchers have compiled evidence suggesting conflict is negatively related to family functioning. For example, marital conflict is associated with several negative outcomes among children including behavioral problems, poor health, low-self esteem, and poor psychological function (Katz \& Woodin, 2002). Couples with increased levels of hostility and detachment were more likely to engage in negative parenting practices, have less cohesive families, be less playful, and have more problems with their children's behavior (Katz \& Woodin). When couples engage in hostile and 
withdrawing communication patterns, their children are more likely to exhibit higher levels of negative emotional responses and noncompliance (Katz \& Woodin).

Family functioning and communication. As explained by the McMaster Model, communication is a key element of family functioning. Research on couple communication illustrates communication patterns are different between healthy functioning couples and distressed couples (Katz \& Woodin, 2002; Gottman, 1994). According to Gottman and Levenson (2000), couples with higher levels of negative affect were more likely to divorce in the first seven years of marriage whereas couples with low levels of both negative and positive affect were more likely to divorce within 14 years of marriage. Quality of family relationships also appeared to decrease after divorce. Parents reported lower levels of family functioning post divorce, including greater difficulty in raising children, greater parental role strain, and less authoritative parenting (Amato, 2000). Amato and Previti (2003) also report communication problems are commonly cited as reasons for divorce.

In terms of family satisfaction, communication with parents, particularly mothers, significantly contributes to family satisfaction levels reported by undergraduate college students (Ghali, 2009). Furthermore, parent-child communication can provide a certain level of protection and deterrence from delinquent child behavior. For example, specific parent-child communication about alcohol use can deter and reduce child use of alcohol (Miller-Day \& Kam, 2010). Furthermore, the communication benefits of family dinner among families with sixth graders are protective through the eighth grade (Fulkerson et al., 2010).

Electronic media have garnered increasing attention as researchers seek to understand their effect on communication. Text messages, e-mails, and instant messaging via the Internet have been some of the focus areas of this new line of research. Studies show text messages, or 
"short type-written messages or photographs sent via mobile phones," are "primarily used in personal relationships" to "commence, advance, maintain, or otherwise influence interpersonal relationships" (Pettigrew, 2009, p. 698). Communicating via text message has increased respondents' sense of connectedness by allowing family members to communicate in environments and situations that did not allow voice communication (Pettigrew). In romantic relationships, husbands and wives also report an increased sense of connectedness and increase in communication attributable to text messaging (Pettigrew). Similarly, e-mail and instant messaging are relation-based (Pettigrew). E-mail communication however, usually entails a longer, more detailed exchange of information that does not need an immediate response, and has been characterized for less close relationships (Kim, Kim, Park, \& Rice, 2007).

Leisure and family functioning. Research examining the relationship between family functioning and family leisure has garnered increasing attention over the last decade. The surge in research has focused on how leisure influences family health and well-being, as well as how family leisure is related to outcomes such as family functioning and family life satisfaction (Mactavish \& Schleien, 2004; Orthner \& Mancini, 1990; Poff et al., 2010; Zabriskie \& McCormick, 2001). Historically, family leisure research has determined there is a positive correlation between family leisure and outcomes such as family functioning and family life satisfaction (Holman \& Epperson, 1984; Orthner \& Mancini). Research indicates positive relationships exist between family leisure, cohesiveness, overall satisfaction with quality of family life, healthy couple relationships, and healthy relationships between parents and their children, as well as family strength (Orthner \& Mancini; Mactavish \& Schleien; Zabriskie \& McCormick). One researcher went so far as to say "in modern society, leisure is the single most important force developing cohesive healthy relationships between husbands and wives and 
between parents and their children" (Couchman, 1988, as cited in Canadian Parks/Recreation Association, 1997, as cited in Freeman and Zabriskie, 2003, p. 75). The majority of these studies, however, have utilized statistical analyses that account for individual-level variance only. It is the intent of this research to build upon this existing research by utilizing a statistical analysis that will account for family-level variance. Media is one type of leisure that significantly relates to family functioning.

Family functioning and media use. Research suggests some negative aspects of family life such as increased levels of perceived stress are related to poorer family functioning and unhealthy use of media (Kennedy, Chen, \& Charlesworth, 2007). Overall maternal fatiguewhich is related to poorer family functioning — is also related to increased media time (Kennedy et al.). Some research indicates viewing televised sports is associated with an increase in family violence (as cited in Perse, 2001). Watching television can also become a ritualized family activity that is a planned family meeting time (Silverstone, 1993); however, the activity is still considerably more passive. Kubey (1990) found greater amounts of passive leisure had a spillover effect for higher-viewing families, meaning that when engaged in non-television viewing activities, high-viewing families were less engaged than light-viewing families.

Similar mixed results exist in the relationship between Internet use and family relationships. Some researchers have determined the Internet provides increased opportunities for family interaction, communication, and collaboration, thereby strengthening the family (Mesch, 2006). Conversely, other research reports increased time spent online decreases time parents and children spend together because the Internet displaces other activities. Furthermore, some research indicates frequent Internet use is associated with an increase in family conflict 
while low Internet use is associated with improved relationships among adolescents, their parents, and friends (Mesch).

\section{Mass Media: A Definition and Overview}

Understanding media is central to understanding its relationship to leisure and family functioning. The term "mass media" evokes images of newspapers, magazines, books, and other print media, as well as electronic forms of media, such as television, the Internet, and radio. Print media, facilitated by the introduction of the printing press, are considered the origin of mass media (Stanton, 1949). The printing press allowed for thoughts, ideas, and information to be communicated more freely and with greater reach than ever before. However, with the advent of electronic mass media (e.g. the radio, television, and the Internet), the realm of mass communication took an "enormous forward step" in speed, potential audience penetration, availability, and low unit cost (Stanton, p. 217). Each of these examples-diverse as they arefall under the umbrella of mass media (Kepplinger, 2008).

Despite their diversity, mass media share four basic characteristics: (a) broad appeal, (b) speed, (c) availability, and (d) low unit cost (Stanton, 1949). The very term mass infers broad appeal to a large and diverse audience; mass media must attract an audience from varied demographic backgrounds. In terms of speed, mass media must be delivered in a timely manner. For example, Stanton contrasted mass media to sculptures; though both are effective and durable in communicating messages, the planning, designing, and completing of a sculpture is considerably more time intensive than tuning into a radio broadcast. Availability also encompasses an element of time. Mass media must be available in various geographic locations, as well as at various times, and preferably communicates its messages through multiple sensory channels (i.e., audio and visual). Finally, mass media must be low-cost. For example, 
magazines provide low-cost avenues of communication to publishers, subscribers, and advertisers (Stanton).

Other researchers have added to Stanton's (1949) basic definition of mass media. Thompson (1995) defined mass communication as "the institutionalized production and generalized diffusion of symbolic goods via the fixation and transmission of information or symbolic event" (p. 26). Thompson added a caveat to his definition: the term mass communication can be assumption-laden and ambiguous. As he pointed out, the term mass can be, at times, misleading; it conjures up images of audiences numbering in the thousands or millions. The term is better defined, not by the number of individuals who access or use media products, but "rather that the products are available in principle to a plurality of recipients" (Thompson, p. 24). Thompson also illuminated a frequent assumption associated with the term mass; he pointed out that the mass of potential recipients is not made up of passive, homogenous individuals. Rather, these individuals are actively engaged in critiquing, interpreting, and incorporating the mass media they consume.

\section{Media Use and Trends}

Consuming media has become a way of life for most Americans. Mass media has become an integral part of day-to-day life and researchers estimate that about half of people's free time is spent in media use; sports and various leisure activities claim approximately $8 \%$; social interaction about 18\%; and "walking, resting and attending 'spectacles' the rest" (Jeffres, Neuendorf, \& Atkin, 2003, p. 169). American youth between the ages of 8 and 18 engage in an estimated average of about 8 hours of media use each day (Roberts \& Foehr, 2008). American adults average approximately 4.5 hours of television use each day (Brock, 2007). 
The rapid spread of TV may have contributed to its archetypal status. According to Roberts and Foehr (2008), the distribution of television sets in the United States increased from $0.5 \%$ of households in 1946 to $55 \%$ a mere decade later. By 1960, 87\% of American households owned a television set. And by 2001, the U.S. Census Bureau estimated there were 2.4 TV sets per household (Roberts \& Foehr). The Nielsen Company (2010), a leading media research group, reported Americans watch more than 35 hours of TV per week. Contributing to overall viewing time are new viewing technologies that have expanded the reach of television, making it more accessible. The Nielsen Company (n. d.) has acknowledged this change in the way it measures television viewing by including computers and mobile devices as avenues for television viewing.

In addition to increased television ownership and viewing, Internet use has increased exponentially since it hit popular culture in 1994 (Montgomery \& Faloutsos, 2001). The number of Web servers grew from two million in 1994 to more than 110 million in 2001, to 2 billion in 2010 (Internet World Stats, 2010; Mongtgomery \& Faloutsos). Other forms of media are also experiencing similar growth trends. Online gaming and video games are one of the fastest growing forms of recreation (Roy, 2009).

\section{Effects of Mass Media}

Researchers argue consuming so many types of media in such large quantities is bound to affect individuals, societies, and cultures. After all, "it makes common sense that anything that consumes so much money... and time...must have some impact on our lives" (Perse, 2001, p. 4). In fact, the question of whether media have effects is no longer valid, and "it is clear that mass communication is an agent or catalyst to a variety of shifts and changes in people and institutions" though "most communication scholars would be reluctant to argue that mass media 
are the sole or most substantial change agent in society" (Perse, p. ix). While it would be impossible to identify or categorize all types of potential media effects, studying media effects enables researchers to better understand how media effects occur and thereby enhance positive effects while lessening negative effects (Perse).

In light of this, research over the last several decades has focused on how mass media affects individuals, societies, and families as well as the duration and strength of those effects. The study of media effects has rendered a vast, though occasionally shallow, pool of accumulated research on media effects. For example, much to the detriment of media effects research, the majority of study has dealt with media effects on the individual level, or microlevel, only. This is in fact, "a fallacy, however, to assume that all media effects are accumulations of individual-level effects. Scholars recognize that a focus solely on individuallevel media effects can obscure more subtle societal-level effects" (Perse, 2001, p. 18). The most important effects may lie under-studied and undiscovered at the "societal, institutional, or cultural level" (Perse, p. 18). There is a need for more media effects extending beyond individual-level effects.

Researchers have identified three types of media effects: cognitive, affective, and behavioral, cognitive effects are those that concern the acquisition of information - what people learn, how beliefs are structured (or restructured) in the mind, how needs for information are satisfied or not. These effects include concerns about what is learned as well as how much is learned. Whereas news and public affairs information is often the focus of cognitive effects, the cognitive impact of entertainment is also an important area of study. Affective effects involve the formation of attitudes, or positive or negative evaluations 
about something. Other areas of affective effects concern emotional reactions to media content, such as fright or amusement, or the development of feelings toward other objects as a result of media exposure, such as the generation of fear in society as a result of watching violent television programming. Behavioral effects are observable actions that are linked to media exposure. (Perse, p. 3)

Still, individual level media effects research forms an important foundation for further societal, institutional, and cultural study. Existing research has identified individual level media effects in the following categories: (a) physical effects; (b) psychological and emotional effects; (c) effects on attitudes and values, emotions, and social behavior; and (d) effects on public opinion (Grimm, 2008; Kepplinger, 2008). These types of media effects will be reviewed and the strength and duration of media effects will be discussed.

Physical effects. Several studies on the physical effects of media use have identified a relationship between media and rising childhood and adult obesity rates (Robinson \& Godbey, 1999; Tucker \& Friedman, 1989). In general, there is a positive correlation between the amount of time spent watching television and being overweight or obese in various age populations (Caroli et al., 2004). Specifically, Tucker and Friedman found that after controlling for age, smoking status, length of work week, physical fitness, and reported hours of exercise per week, adult males who viewed more than three hours of television a day were twice as likely to be obese than adult males who viewed less than one hour per day. Adult males who viewed between one and two hours of television per day were 1.6 times as likely to be obese as those who viewed less than one hour.

Comparatively, when controlling for the same variables and education, Tucker and Bagwell (1991) found adult females who viewed three to four hours of television a day showed 
almost twice the prevalence of obesity. Women who watched more than four hours of television per day showed a prevalence of obesity more than twice the reference group of less than one hour of television per day. In children, television has been consistently related to childhood obesity in cross-sectional, longitudinal, and intervention studies (Dennison \& Edmunds, 2008).

Similarly, Vandelanotte et al. (2009) found individuals who were classified as high leisure-time Internet and computer users were 1.46 times more likely to be overweight, and 2.52 times more likely to be obese when compared to individuals who reported no Internet or computer use. This trend held true even for adults who were highly active in their leisure time.

Psychological and emotional effects. Psychologically, there are several effects of media use. For example, Dworak, Schierl, Bruns, and Struder (2007) determined school-aged children who viewed television and were exposed to computer games experienced abnormal sleep architecture, poor sleep continuity, and deteriorated memory performance. Furthermore, Christakis, Zimmerman, DiGiuseppe, and McCarty (2004) found children who were exposed to television during early childhood were more likely to suffer from attention problems, like hyperactivity, at age seven years.

Neuman (1986) analyzed the home learning environment in terms of children's TV viewing habits and leisure reading preferences. She surveyed fifth graders to determine their home media habits in degrees of television viewing and reading. According to combined categories of viewing and reading, as well as the results of the home environmental questionnaire administered to parents, there was a significant relationship between media behavior and certain family patterns (Neuman). It appeared children adopted and internalized their parents' media habits and attitudes. 
Effects on attitudes and values, emotions, and social behavior. In addition to physical and psychological effects, researchers have examined effects of media on social behavior, attitudes, values, and emotions. Katz, Gurevitch, and Haas (1973) suggested media could potentially satisfy needs such as social understanding and identity, reinforcing social status, and strengthening social ties. Scholars have also suggested engagement in needs gratification (or nongratification) behaviors through media impacts society and the individual (Ruggiero, 2000). The process of gratification thereby becomes a cycle, repeated as new perceived problems and solutions arise (Ruggiero).

Certain social behaviors and phenomenon such as parasocial interaction, mean world syndrome, and relational aggression, are also related to needs gratification through media use. For example, parasocial interaction is an imagined or one-sided interaction from a viewer to a media character engaged in as if the communication were mutual (as cited in Wang, Fink, \& Cai, 2008). This type of interaction with media typically stems from loneliness and a desire to fulfill otherwise unmet interpersonal needs (Wang et al.). Researchers have also identified a relationship between media use and aggressive tendencies. Mean world syndrome is one example of that relationship. Mean world syndrome is characterized in individuals by the belief that the world is a violent and dangerous place (Scharrer \& Leone, 2006). Anderson et al. (2003) also found a relationship between viewing violence in the media and an increase in aggressive thoughts and behavior (short and long term). Viewing relational forms of aggression in the media can also affect both physically and relationally aggressive behavior (Coyne et al., 2008).

Parental media monitoring. Parental media monitoring may mediate the effects discussed earlier. For example, Kennedy et al. (2007) reported "the family communication climate may block some of the harmful effects of sexual media content on adolescents' moral 
development (p. 13). Warren et al. (2002) suggest children are "best equipped to resist negative viewing effects when they become critical viewers"- a skill parents can help teach their children (p. 87).

In spite of empirical evidence suggesting the effectiveness of parental media monitoring, media monitoring practices are not employed by all parents (Warren et al., 2002). There are several determinants of parental media monitoring, including parental involvement, parents' attitudes toward media, and certain demographic indicators like child age (Nikken \& Jansz, 2006; Warren et al.). Kennedy et al. (2007) also reported overall maternal fatigue levels are related to less media monitoring and increased media time.

\section{Mass Media in Context of Leisure}

As established, mass media is commonly used as entertainment and leisure. Leisure, like mass media, can have significant effects on various physical, social, and psychological outcomes. Leisure significantly relates to family health and well-being, family functioning, family life satisfaction, overall satisfaction with or quality of family life, healthy couple relationships, healthy relationships between parents and their children, family strength, physical and psychological health, as well as social behaviors, emotions, and attitudes and values (Carpenter, 1994; Mactavish \& Schleien, 2004; Mannell, 2007; Orthner \& Mancini, 1990; Patterson \& Carpenter, 1994; Poff et al., 2010; Siegenthaler, 1997; Zabriskie \& McCormick, 2001). Furthermore according to Wells, Widmer, and McCoy (2004), "family recreation is one modality that can promote positive parent-adolescent interaction" (p. 328). Of particular interest, shared family recreation facilitates important aspects of family functioning such as “communication, interaction, and problem solving" (Wells et al., p. 328). A growing body of research indicates leisure can "positively influence physical, psychological and spiritual health" 
(Mannell, p. 114). Furthermore, participation in personally meaningful leisure activities can buffer life's stressful events (Siegenthaler). Leisure can be an effective moderator of traumatic life events (e.g. divorce, death of a spouse, change in financial status, illness, and change in job; Carpenter; Hutchinson, Afifi, \& Krause, 2007; Patterson \& Carpenter). In addition, research indicates leisure enhances physical health, mental health, and psychological well-being (Siegenthaler).

Some of the earliest and continuing leisure research has tried to determine whether specific types of leisure are more likely to render the positive outcomes discussed above than others. For example, Nash (as cited in Russell, 1996) strongly argues a hierarchy of leisure activities exists. His hierarchy of leisure activities shows creative activity is the most valuable leisure pursuit while acts against society (i.e., criminal activities) are the lowest. Watching television, the primary form of entertainment of more than half of all Americans, ranks only above injury or detriment to self in the entertainment, amusement, escape, or killing time category. Nash categorized it as "spectatoritis," a level where "no active, creative, or deeply memorable experiences" are experienced (Brock, 2007, p. 15). Too many of these types of activities can restrict individual and group progress and development.

Csikszentmihalyi (1990) found similar trends in his research. In his studies of flow and optimal experience, Csikszentmihalyi reported people who engaged in watching television experienced "some of the lowest levels of concentration, use of skills, clarity of thought, and feelings of potency" (p. 30). Conversely, challenging activities “provide opportunities for overwhelming mastery experiences" (Wells et al., 2004, p. 328). Family service expeditions, studied specifically in context of family leisure, often incorporated a level of challenge, including substantial family sacrifice that increased family strength and positively impacted 
other facets of family life in what researchers described as a family deepening process (Palmer, Freeman, \& Zabriskie, 2007). Shaw and Dawson (2001) similarly recognized important characteristics of meaningful family leisure. They categorized family leisure as leisure that is not necessarily freely chosen or intrinsically motivated; but rather planned, organized, and facilitated by parents in order to achieve particular short-term and long-term goals. They called this purposive leisure, noting parents engaged in this type of leisure to achieve family goals.

The changing leisure landscape. Mass media have influenced leisure patterns, including family leisure patterns. In fact, Robinson (1969) stated "television has had a massive impact on American daily life, responsible for a greater rearrangement of time usage than the automobile” (p. 211). Brock (2007) stated decisively, “TV viewing is American's number one recreational pursuit" and suggested a shift in cultural attitudes toward leisure have made television America's preferred recreation activity (p. 3).

Coffin (1948) published one of the first studies on television's effects on leisure. He reported families who owned television sets had lower rates of participation in out-of-home activities than families without sets. Furthermore, he noted television was replacing other previously engaged in "at-home" activities. Coffin predicted that as television became "more accessible to increasing numbers in the population it may bring with it noticeable effects on the family's activities in and out of the home" (p. 558).

To a certain extent, Coffin's (1948) predictions are coming to fruition. Media increasingly claim the leisure and recreation time of adults and youth because, as some researchers suggest, "new technologies have increased the mass media menu from which people may select" (Jeffres et al., 2003, p. 169). As this menu has increased, adults, youth, and families have learned to rely more on media for leisure and recreation. For example, video games have 
quickly risen in popularity and have "become the fastest growing form of human recreation" (Ryan et al., 2006, p. 347). Internet use has also increased (Montgomery \& Faloutsos, 2001). More than 266 million people in North America use the Internet and nearly 2 billion people worldwide (Internet World Stats, 2010).

Media as family leisure. Media has clearly become a mainstay of the home and family, and "if we wish to understand family time, we need to understand 'family-plus-media.' Specifically, the "media has moved in with the family and has become one of its core components"” (Daly, 1996, p. 76). Because media plays such a large role in family life, it is important to study and understand its relationship to family outcomes such as family functioning.

There are positive and negative aspects of using mass media as family leisure. Csikszentmihalyi and Kubey (1981) reported that among a sample of adults employed full-time, television watching was the least challenging activity they engaged in and the one that required the fewest skills. When watching television as a family however, the challenge increased considerably. Other research has rendered mixed results as well. For example, some research indicates watching television as a family creates a passive and one-dimensional experience (Daly, 1996). Conversely, other research has determined television may be "linked to more frequent and positive family interactions" (Daly, p. 77). Families who can be categorized as heavy TV viewers have reported more time spent together than light viewers (Larson, Kubey, \& Colletti, 1989).

Spending more time together may not translate into an increase in family interaction. Kubey (1990) found family conversations decreased by $40 \%$ when watching TV as compared to all other non-television activities. Dempsey (2005) also reported that families interact more when engaged in activities other than watching TV, and that for every 1 hour increase in TV 
viewing, adolescents spend 6 minutes less in conversation with their parents. Brock (2007) clarified further, stating "watching television is a fundamentally solitary activity" (p. 20). Bovill and Livingstone (2001) agree and suggest that while television is still a family medium, the "future trajectory for television would seem to be towards increasingly solitary use" (p. 14). This suggests the way in which media is used by the family and its individual members (i.e., together or separately) may be an important factor in understanding the relationship between media and family.

The way in which couples use media as recreation is of particular importance to marital satisfaction. In the case of video gaming, "the ways in which couples participated and perceived the gaming activity" were more influential on marital satisfaction than overall time spent playing video games (Ahlstrom, Lundberg, Zabriskie, Eggett, \& Lindsay, 2009, p. 19). Furthermore, the way parents use media as leisure with their children is also of particular importance to their relationships. One study suggests daughters who play age-appropriate video games with their fathers report stronger mental health, a stronger sense of family connectedness, and exhibit better behavior (Coyne et al., 2011). Additionally, the use of other media such as texts, e-mail, and Internet-based instant messaging may facilitate communication between family members (Pettigrew, 2009). Thus, while the passiveness of television viewing may leave something to be desired in family leisure outcomes, perhaps other forms of media may actually facilitate positive outcomes. Still, the ability of media as leisure to produce positive outcomes such as increased family functioning remains in question.

Leisure research has clearly established a positive relationship between leisure and positive outcomes. Specifically, scholars have repeatedly found a positive relationship between family leisure and family functioning. Researchers, however, have largely ignored media use as 
family leisure even though media use represents a significant proportion of leisure activity. The proposed research will take a step toward filling this gap in leisure research. Furthermore, there is a gap in research concerning the effects of media on the family. While media effects research has clearly identified relationships between media and various outcomes such as physical health, psychological and emotional well-being, and attitudes and values, social behavior and public opinion, these have been examined solely on the individual level, focusing on youth and adults separately (Caroli et al., 2004; Grimm, 2008; Kepplinger, 2008; Vandelanotte et al., 2009). The research and analysis in this proposal will examine media effects from an individual-level of analysis. Moreover, because the data is nested in families, family-level methods of analysis will be incorporated to more systematically account for the variance, and thus begin to fill this gap as well.

Therefore, the purpose of this study is to examine the relationship between media as family leisure and family functioning among families with at least one adolescent child. Specifically, this study will attempt to examine the relationship between family functioning and media use, media connection, and media monitoring from a nested data approach. Furthermore, because the data is nested in families, and because most family leisure research has been limited to individual-level analyses, this study will incorporate higher level statistics (multi-level modeling) which will account for family-level variance in the data analysis in addition to accounting for individual-level analysis. 


\section{Chapter 3}

\section{Methods}

The problem of this study is to examine the relationship between media as family leisure and family functioning among families with at least one adolescent child. Specifically, this study will attempt to examine the relationship between family functioning and media use, media connection, and media monitoring. Furthermore, because the data is nested in families, and because most family leisure research has been limited to individual-level analyses, this study will incorporate higher level statistics (multi-level modeling) which will account for family-level variance in the data analysis in addition to accounting for individual-level analysis. As previously stated, exploring the relationship between the media habits of youth and family functioning will add to the body of literature on strengthening families through leisure as well as the research on media effects in the family. This chapter outlines: (a) sample, (b) instrumentation, (c) data collection procedures, and (d) analysis.

\section{Sample}

The participants for this study were taken from waves three and four of the Flourishing Families Project (FFP), a longitudinal study of inner-family life involving families with a child between the ages of 11 and 16. The sample was taken from a large northwestern city and consists of 500 families (91.8\% retention from wave 1) with a child within the target range (330 two-parent families and 139 single-parent families). At wave four, participant children averaged 14.29 years of age, while mothers averaged 47.1 years and fathers averaged 49.3 years in age. Two hundred ninety-eight families (64.9\%) were of European American ethnicity, 56 (12.2\%) were African American, with a smaller number for Hispanics (1) and Asian Americans (4). Eighty-nine (19.3\%) families are categorized as multi-ethnic, based on a combination of two or 
more ethnicities among family members. In terms of parental education, $60.9 \%$ of mothers and approximately $69.7 \%$ of fathers had a bachelor's degree or higher. Related to yearly family income, $22.6 \%$ of families reported making less than $\$ 59,000 ; 32.8 \%$ reported income in the $\$ 60,000-99,000$ range; $29.9 \%$ reported income in the $\$ 100,000-149,000$ range, with another $14.7 \%$ making $\$ 150,000$ or more per year. Approximately $32 \%$ of single parents had never been married, $8.7 \%$ were separated, $49.3 \%$ were divorced, and $4.3 \%$ were widowed (Day et al., 2010).

\section{Instrumentation}

The variables of interest in this study are family functioning, media use, media monitoring, family conflict, and various demographic questions. The McMaster Family Assessment Device (FAD) was used to measure family functioning (Epstein et al., 1983). The Media in the Home scale was used to measure media use and media connection from a youth perspective.

McMaster Family Assessment Device. Elements of family functioning were measured using the McMaster Family Assessment Device (Epstein et al., 1983). The McMaster Family Assessment Device is made up of seven subscales with a total of 53 items (Epstein et al.). A revised version of the FAD was used consisting of 20 items, including the entire General Functioning and Affective Responsiveness subscales and two items from the Affective Involvement subscale for the sake of questionnaire brevity. Respondents answered how much they agreed or disagreed with statements about their family using a four-point Likert scale ranging from strongly disagree to strongly agree, with higher scores indicating better family functioning (Day et al., 2010).

This is a general assessment of family functioning and one of the subscales within this measure will be used to measure affective connection between the parents. This will also provide 
a well established and known valid family systems assessment measure to make comparisons with the newer family system measures that have been included in the study.

Initial evidence of construct validity was established in other studies. Reliabilities have been found to range from .73 to .83 for the three subscales from which items were taken (Kabacoff, Miller, \& Bishop, 1990). For this sample, Cronbach's alpha coefficients are as follows: (a) parent one $(\mathrm{P} 1)=.893$, parent two $(\mathrm{P} 2)=.903$ (overall measure); (b) $\mathrm{P} 1=.879, \mathrm{P} 2$ $=.880$ (General Functioning subscale); and (c) P1 =.830 and P2 =.843 (Affective Response subscale; Day et al., 2010). Taken together, the FAD reports the necessary psychometric properties to make valid and reliable inferences regarding family functioning.

Media in the home. The Media in the Home Scale is an instrument developed specifically for the Flourishing Families Project. It is designed to measure media connection and media use from a youth perspective (Day et al., 2010).

Media connection. This scale was used with parents and children to determine how often they used media or technology to connect and communicate with each other. Parents and children responded to a 5-item measure using a 6-point Likert scale ranging from 1 (never) to 6 (more than once a day). Sample items included, "How often do you email your parent/child," "How often do you use social networking sites (such as Facebook) to connect with your parent/child," "How often do you text or call your child on a cell phone," and "How often do you watch TV or movies with your parent/child?” Items were analyzed individually for frequency of use (Day et al., 2010).

Media use. Participants noted how many hours they spend in a typical day using specific media activities including watching TV programs, playing video games, reading books or 
magazines, and texting on a cell phone. Response categories ranged from 1 (none) to 9 (more than 8 hours; Day et al., 2010). Responses were totaled to estimate total time spent using media.

Parental media monitoring. Parent self-reports were used to assess parental monitoring of children's media exposure using a 7-item measure based on past assessments of child media use (Nikken \& Jansz, 2006; Warren et al., 2002). Participants responded by rating how often they engaged in specific monitoring behaviors using a 5-point Likert scale ranging from 1 (never) to 5 (very often). Higher scores reflect greater monitoring of children's media exposure and sample items included, "Tell your child to turn off media when you think it is inappropriate," and "Explain reasons why media characters do what they do." For the current sample, Cronbach's alpha reliability coefficients were found to be .663 (P1) and .670 (P2).

Youth were also asked to report parental media monitoring using a similar scale. Participants responded to seven items, rating how often their parents engaged in specific monitoring behaviors, using a 5-point Likert scale ranging from 1 (never) to 5 (very often). Higher scores reflect greater perceived monitoring of children's media exposure. Sample items included, "tell you to turn off media when they think it is inappropriate," "try to help you understand what you see in the media" and, "explain reasons why media characters do what they do." For the current sample, the reliability coefficient (Cronbach's alpha) for the entire scale was .820.

Other variables of interest. The media variables are the independent variables of special interest to this study. The following variables (a) family conflict, (b) depression, and (c) anxiety are independent variables that have been shown to significantly contribute to family functioning. The proposed model will include them so as to more specifically partition variance among the variables. 
Demographic information. Demographic questions were included to provide potential controlling factors and identify primary characteristics of the sample. Examples of demographic data that was collected are income, race, age, marital status, and gender.

\section{Data Collection Procedures}

Participant families for the FFP were selected from a large northwestern city and a midsized western city. They were interviewed during the first eight months of 2007. Families were primarily recruited using a purchased national telephone survey database (Polk Directories/ InfoUSA). This database claims to contain 82 million households across the United States and has detailed information about each household, including presence and age of children. Families identified using the Polk Directory were selected from targeted census tracts that mirrored the socio-economic and racial stratification of reports of local school districts. All families with a child between the ages of 10 and 14 living within target census tracts were deemed eligible to participate.

Eligible families were subsequently contacted directly using a multi-stage recruitment protocol. First, a letter of introduction was sent to potentially eligible families. Second, interviewers made home visits and phone calls to confirm eligibility and willingness to participate in the study. Once eligibility and consent were established, interviewers made an appointment to come to the family's home to conduct an assessment interview.

In addition to the random selection protocol used with the survey database, families were recruited through family referral. At the conclusion of their in-home interviews, families were invited to identify two additional families in the recruitment area that matched study eligibility. This type of limited-referral approach permitted researchers to identify eligible families in the targeted area that were not found in the Polk Directory. The Polk Directory national database 
was generated using telephone, magazine, and Internet subscription reports; therefore, families of color (especially those of lower socio-economic status) were underrepresented in the database. By broadening our approach and allowing for some limited referrals, we were able to significantly increase the social-economic and ethnic diversity of the sample.

Six hundred and forty families agreed to participate. The most frequent reasons cited by families for not wanting to participate in the study were lack of time and concerns about privacy. It is important to note that there were very little missing data. As interviewers collected each segment of the in-home interview, questionnaires were screened for missing answers and double marking.

\section{Analysis}

Data will be analyzed using the Statistical Package for Social Sciences (SPSS) Version 18.0 computer software and lme4 library in $\mathrm{R}$ will be loaded so the lmer( ) function can be implemented (R Development Core Team, 2010). The lmer( ) function is used to analyze linear mixed effects models (Pinheiro \& Bates, 1996).

First, basic descriptive statistics of the demographic data will be calculated in SPSS, including the mean and median values of the dependent and independent variables. Family functioning will be the dependent variable. Independent variables of particular interest include parental media monitoring and media connection, which includes media communication. The model will include other independent variables such as family conflict, depression, anxiety, BMI, and demographics in addition to the key media independent variables. This will allow us to more specifically partition out variance explained by each variable and determine the nature of the relationship between those variables and family functioning. 
Because the data are nested in families, we will employ an analytical method that will account for the different levels of variance. Multilevel models (MLM) will account for individual-level attributes (parent one, parent two, and child), then for group (family) level attributes. Thus, variance components will be estimated for families and for individuals within families. Statistical significance will be assessed using the likelihood ratio test paradigm as implemented in R (R Development Core Team, 2010). In the field of family leisure research, this type of statistical analysis is deficient. Researchers have noted the need for models that account for family-level variance (Poff et al., 2010).

The relationship of two additional independent variables to the outcome variable of family functioning will be analyzed separately. Data for the media use variables were collected only for youth in Wave 3 of FFP. When using MLM, all cases in the analysis must have the same number of variables, and the same variables must exist for all individuals and groups. This allows the extraction of individual and family level variance. The relationship between media use and family functioning cannot be examined using MLM because the data only exist for youth making it impossible to extract family level variance. The relationship between media use and family functioning, however, is of particular interest to this study, and therefore will be included in the analysis. The relationship will be analyzed using a linear regression model that accounts for the other independent demographic variables. These linear regression models will be approximated using SPSS. The descriptive statistics, MLM results, and linear regression model results will be interpreted and written up and presented in a formal document. 


\section{References}

Agate, J. R., Zabriskie, R. B., Agate, S. T., \& Poff, R. (2009). Family leisure satisfaction and satisfaction with family life. Journal of Leisure Research, 41(2), 205-223.

Ahlstrom, M., Lundberg, N. R., Zabriskie, R., Eggett, D., \& Lindsay, G. B. (2009). Me, my wife, and my Avatar: The relationship between marital satisfaction and playing massively multiplayer online role-playing games (MMORPGs). Unpublished manuscript, Department of Recreation Management Youth Leadership, Brigham Young University, Provo, Utah, United States.

Amato, P. (2000). The consequences of divorce for adults and children. Journal of Marriage and the Family, 62, 1269-1287.

Amato, P. R., \& Previti, D. (2003). People's reasons for divorcing: Gender, social class, the life course, and adjustment. Journal of Family Issues, 24(5), 602-626.

Anderson, C. A., Berkowitz, L., Donnerstein, E., Huesmann, L. R., Johnson, J. D., Linz, D., . . \& Wartella, E. (2003). The influence of media violence on youth. Psychological Science in the Public Interest, 4(3), 81-110.

Bovill, M., \& Livingstone, S. M. (2001). Bedroom culture and the privatization of media use. London, England: LSE Research Online.

Brock, B. (2002). Life without TV: Filling those four hours with more satisfying leisure. Parks and Recreation, 37(11), 68-73.

Brock, B. (2007). Living outside the box: TV-free families share their secrets. Spokane: Eastern Washington University Press.

Burns, D. D. (1989). The feeling good handbook. New York, NY: William Morrow \& Co.. 
Caroli, M., Argentieri, L., Cardone, M., \& Masi, A. (2004). Role of television in childhood obesity prevention. International Journal of Obesity, 28, S104-S108.

Carpenter, G. (1994). Leisure and health during middle adulthood: A case-study. In D. M. Compton \& S.E. Iso-Ahola (Eds.). Leisure \& Mental Health, Vol. 1, (pp. 98-111). Park City, UT: Family Development Resources.

Christakis, D., Zimmerman, F. J., DiGiuseppe, D. L., \& McCarty, C. A. (2004). Early television exposure and subsequent attentional problems in children. Pediatrics, 113(4), 708.

Coffin, T. E. (1948). Television's effects on leisure-time activities. Journal of Applied Psychology, 32(5), 550-558.

Coyne, S. M., Nelson, D. A., Lawton, F., Haslam, S., Rooney, L., Titterington, L., . . \& \& Ogunlaja, L. (2008). The effects of viewing physical and relational aggression in the media: Evidence for a cross-over effect. Journal of Experimental Social Psychology, 44(6), 1551-1554.

Coyne, S. M., Meng, N., Harper, J., Nelson, D. A., \& Keister, E. (2008). TV violence and abuse in romantic relationships: The importance of relational aggression. Poster presented at the International Society for the Study of Behavioural Development XX World Meeting, Wurzburg, Germany.

Coyne, S. M., Padilla-Walker, L. M., Stockdale, L., \& Day, R. D. (2011). Game on...girls: Associations between co-playing video games and adolescent behavioral and family outcomes. Journal of Adolescent Health. In press.

Csikszentmihalyi, M., (1990). Flow: The psychology of optimal experience. New York, NY: Harper \& Row. 
Csikszentmihalyi, M., \& Kubey, R. (1981). Television and the rest of life: A systematic comparison of subjective experience. Public Opinion Quarterly, 45(3), 317.

Daly, K. (1996). Families \& time: Keeping pace in a hurried culture. Thousand Oaks, CA: Sage.

Day, R. D., Bean, R., Harper, J., Miller, R., Walker, L., Yorgason, J., \& Coyne, S. (2010). Codebook - wave III (7-15-10): Greater Seattle area. Flourishing Families Project: Survey of Family Life.

Dempsey, N. P. (2005). Television use and communication within families of adolescents. In B. Schneider \& L. Waite (Eds.), Being together, working apart (pp 277-296). New York, NY: Cambridge.

Dennison, B., \& Edmunds, L. S. (2008). The role of television in childhood obesity. Progress in Pediatric Cardiology, 25, 191-197.

Dworak, M., Schierl, T., Bruns, ,T., \& Struder, H. K. (2007). Impact of singular excessive computer game and television exposure on sleep patterns and memory performance of school-aged children. Pediatrics, 120(5), 978-985.

Elkind, D. (2007). The power of play. Philadelphia, PA: Da Capo Press.

Epstein, N. B., Baldwin, L. M., \& Bishop, D. S. (1983). The McMaster family assessment device. Journal of Marital and Family Therapy, 9, 171-180.

Evans, L., Cowlishaw, S., \& Hopwood, M. (2009). Family functioning predicts outcomes for veterans in treatment for chronic posttraumatic stress disorder. Journal of Family Psychology, 23(4), 531-539.

Franks, P. (1992). Social relationships and health - The relative roles of family functioning and social support. Social Science \& Medicine, 34(7), 779-788. 
Freeman, P., \& Zabriskie, R. B. (2003). Leisure and family functioning in adoptive families: Implications for therapeutic recreation. Therapeutic Recreation Journal, 37(1), 73-93.

Fulkerson, J. A., Pasch, K. E., Stigler, M. H., Farbakhss, K., Perry, C. L., \& Komro, K. A. (2010). Longitudinal associations between family dinner and adolescent perceptions of parent-child communication among racially diverse urban youth. Journal of Family Psychology, 24(3), 261-270.

Garrison, B. G., Blalock, L. B., Zarki, J. J., \& Merritt, P. B. (1997). Delayed parenthood: An exploratory study of family functioning. Family Relations, 46(3), 281-290.

Georgiades, K., Boyle, M. H., Jenkins, J. M., Sanford, M., \& Lipman, E. (2008). A multilevel analysis of whole family functioning using the McMaster Family Assessment Device. Journal of Family Psychology, 22(3), 344-354.

Ghali, M. N. (2009). Attachment to parents, family communication patterns, and family satisfaction in emerging adulthood (Doctoral dissertation). Retrieved from http://proquest.umi.com/pqdlink?Ver=1\&Exp=12-062015\&FMT=7\&DID=1918566981\&RQT=309\&attempt=1.

Gottman, J. M. (1994). What predicts divorce? Hillsday, NJ: Erlbaum.

Gottman, J. M., \& Levenson, R. W. (2000). The timing of divorce: Predicting when a couple will divorce over a 14-year period. Journal of Marriage and the Family, 62, 737-745.

Grimm, J. (2008). Physical effects of media content. In W. Donsbach (Ed.), The international encyclopedia of communication. Retrieved from http://www.communicationencyclopedia.com/subscriber/tocnode?id=g9781405131995_c hunk_g978140513199521_ss36-1 
Holman, T. B., \& Epperson, A. (1984). Family and leisure: A review of the literature with research recommendations. Journal of Leisure Research, 16(4), 277-294.

Hossain, Z. (2001). Division of household labor and family functioning in off-reservation Navajo Indian families. Family Relations, 50(3), 255-261.

Hughes, A. A., Hedtke, K. A., Kendall, P. C. (2008). Family functioning in families of children with anxiety disorders. Journal of Family Psychology, 22(2), 325-328.

Hutchinson, S. L., Afifi, T., \& Krause, S. (2007). The family that plays together fares better: Examining the contribution of shared family time to family resilience following divorce. Journal of Divorce \& Remarriage, 46(3/4), 21-48.

Internet World Stats. (2010, January 6). Internet usage and population in North America. Retrieved from http://www.internetworldstats.com/stats14.htm

Jacobsen, W. C., \& Forste, F. (2010). Cyberpsychology, behavior, and social networking. Ahead of print. doi:10.1089/cyber.2010.0135.

Jeffres, L. W., Neuendorf, K., \& Atkin, D. (2003). Media use and participation as a spectator in public leisure activities: Competition or symbiosis? Leisure Studies, 22(2), 169-184.

Johnson, J.H. (1986). Life events as stressors in childhood and adolescence. Beverly Hills, CA: Sage.

Kabacoff, R. I., Miller, I. W., \& Bishop, D. S. (1990). A psychometric study of the McMaster Family Assessment Device in psychiatric, medical, and nonclinical samples. Journal of Family Psychology, 3(4), 431-439.

Katz, E., Gurevitch, M., \& Haas, H. (1973). On the use of the mass media for important things. American Sociological Review, 38(2), 164-181. 
Katz, L. F., \& Woodin, E. M. (2002). Hostility, hostile detachment, and conflict engagements in marriages: Effects on child and family functioning. Child Development, 73(2), 636-652.

Kennedy, C., Chen, J. L., \& Charlesworth, A. (2007). Maternal health, family functioning and family media practices. Annals of Behavioral Medicine, 33(S1), S117.

Kepplinger, H. M. (2008). Media effects. In W. Donsbach (Ed.), The international encyclopedia of communcation. Retrieved from http://www.communicationencyclopedia.com/subscriber/tocnode?id=g9781405131995_c hunk_g978140513199518_ss29-1

Kim, H., Kim. G. J., Park, H. W., \& Rice, R. E. (2007). Configurations of relationships in different media: FtF, email, instant messenger, mobile phone, and SMS. Journal of Computer-Mediated Communication, 12(4), 1183-1207.

Kubey, R. (1990). Television and the quality of family life. Communication Quarterly, 38(4), 312-324.

Larson, R., Kubey, R., \& Colletti, J. (1989). Changing channels: Early adolescent media choices and shifting investments in family and friends. Journal of Youth and Adolescence, 18(6), 583-599.

Lotz, A. D. (2008). Television. In W. Donsbach (Ed.), The international encyclopedia of communication. Retrieved from http://www.communicationencyclopedia.com/subscriber/tocnode?id=g9781405131995_c hunk_g978140513199525_ss33-1

Louv, R. (2005). Last child in the woods: Saving our children from nature-deficit disorder. Algonquin Books of Chapel Hill: Chapel Hill, N. C. 
Mactavish, J. B., \& Schleien, S. J. (2004). Re-injecting spontaneity and balance in family life: Parents' perspectives on recreation in families that include children with developmental disability. Journal of Intellectual Disability Research, 48(2), 123-141.

Mandara, J., \& Murray, C. B. (2000). Effects of parental marital status, income, and family functioning on African American adolescent self-esteem. Journal of Family Psychology, 14(3), 475-490.

Mandara, J., \& Murray, C. B. (2002). Development of an empirical typology of African American family functioning. Journal of Family Psychology, 16(3), 318-337.

Mannell, R. C. (2007). Leisure, health and well-being. World Leisure Journal, 49(3), 114-128.

McCreary, L. L., \& Dancy, B. L. (2004). Dimensions of family functioning: Perspective of lowincome African American single-parent families. Journal of Marriage and Family, 66(3), 690-701.

Mesch, G. S. (2006). Family relations and the Internet: Exploring a family boundaries approach. The Journal of Family Communication, 6(2), 119-138.

Miller, I. W., Ryan, C. E., Keitner, G. I., Bishop, D. S., \&, Epstein, N. B. (2000). The McMaster approach to families: Theory, assessment, treatment and research. Journal of Family Therapy, 22, 168-189.

Miller-Day, M., \& Kam, J. A. (2010). More than just openness: Developing and validating a measure of targeted parent-child communication about alcohol. Health Communication, 25(4), 293-302.

Montgomery, A. L., \& Faloutsos, C. (2001). Identifying Web browsing trends and patterns. Computer, 34(7), 94-95. 
Neuman, S. (1986). Television, reading, and the home environment. Literacy Research and Instruction, 25(3), 173-183.

Nikken, P., \& Jansz, J. (2006). Parental mediation of children's videogame playing: A comparison of the reports by parents and children. Learning, Media, and Technology, 31, 181-202.

Orthner, D. K., \& Mancini, J. A. (1990). Leisure impacts on family interaction and cohesion. Journal of Leisure Research, 22(1), 125-137.

Orthner, D. K., \& Mancini, J. A. (1991). Benefits of leisure for family bonding. In B. L. Driver, P. J. Brown, \& G. L. Peterson (Eds.), Benefits of Leisure (pp. 215-247). State College, PA: Venture.

Palmer, A. A., Freeman, P. A., \& Zabriskie, R. B. (2007). Family deepening: A qualitative inquiry into the experience of families who participate in service expeditions. Journal of Leisure and Research, 39(3), 438-458.

Patterson, I., \& Carpenter, G. (1994). Participation in leisure activities after the death of a spouse. Leisure Sciences, 16, 105-112.

Perse, E. M. (2001). Media effects and society. Mahwah, NJ: Lawrence Erlbaum Associates. Pedersen, S., \& Revenson, T. A. (2005). Parental illness, family functioning, and adolescent well-being. Journal of Family Psychology, 19(3), 404-419.

Pettigrew, J. (2009). Text messaging and connectedness within close interpersonal relationships. Marriage \& Family Review, 45(6), 697-716.

Pinhiero, J. C., \& Bates, D. M. (1996). Unconstrained parameterizations for variance-covariance matrices. Statistics and Computing, 6, 289-295. 
Poff, R., Zabriskie, R., \& Townsend, J. (2010). Modeling family leisure and family related constructs: A national study of U.S. parent and youth perspectives. Journal of Leisure Research, 42(3), 365-391.

Ponsford, J., \& Schonberger, M. (2010). Family functioning and emotional state two and five years after traumatic brain injury. Journal of the International Neuropsyhcological Society, 16(2), 306-317.

R Development Core Team. (2010). R: A language and environment for statistical computing. R Foundation for Statistical Computing. Vienna, Austria.

Radloff, L. S. (1977). The CES-D scale: A self-report depression scale for research in the general population. Applied Psychological Measurement, 1, 385-401.

Rideout, V. J., Foehr, U. G., \& Roberts, D. F. (2010). Generation $M^{2}$ :Media in the lives of 8- to 18-years olds. Retrieved from Kaiser Family Foundation website http://www.kff.org/entmedia/7251.cfm.

Roberts, D. F., \& Foehr, U. G. (2008). Trends in media use. The Future of Children, 18(1), 1137.

Robinson, J. (1969). Television and leisure time: Yesterday, today, and (maybe) tomorrow. Public Opinion Quarterly, 33, 210-222.

Robinson, J., \& Godbey, G. (1999). Time for life: The surprising ways Americans use their time. University Park: Pennsylvania State University Press.

Roy, S. J. (2009). Internet uses and gratifications: A survey in the Indian context. Computers in Human Behavior, 25, 878-886.

Ruggiero, T. E. (2000). Uses and gratifications theory in the $21^{\text {st }}$ century. Mass Communication \& Society, 3(1), 3-37. 
Russell, R. V. (1996). Pastimes: The Context of Contemporary Leisure. Chicago, IL: Brown \& Benchmark.

Ryan, R. M., Rigby, C. S., \& Przybylski, A. (2006). The motivational pull of video games: A self-determination theory approach. Motivational Emotion, 30, 347-363.

Sawant, N., \& Kamal, J. (2010). Understanding family functioning and social support in unremitting schizophrenia: A study in India. Indian Journal of Psychiatry, 52(2), 145149.

Scharrer, E., \& Leone, R. (2006). I know you are but what am I? Young people's perceptions of varying types of video game influence. Mass Communication \& Society, 9(3), 261-286.

Shaw, S. M., \& Dawson, D. (2001). Purposive leisure: Examining parental discourses on family activities. Leisure Sciences, 23, 217-231.

Siegenthaler, K. L. (1997). Health benefits of leisure. Parks and Recreation, 32(1), 24, 26, 28, $30-31$

Silverstone, R. (1993). Time, information and communication technologies and the household. Time \& Society, 2(3), 283.

Spence, S. H. (1998). A measure of anxiety symptoms among children. Behaviour Research and Therapy, 36, 545-566.

Stanton, F. (1949). Television and people. Education, 70(4), 217-224.

The Nielsen Company (n. d.). Television: How the numbers come to life. Retrieved from http://en-us.nielsen.com/content/nielsen/en_us/measurement/tv_research.html

The Nielsen Company. (2010). Television, Internet, and mobile usage in the US. Three Screen Report, 8, 1-8. 
Thompson, J. (1995). The media and modernity: A social theory of the media. Palo Alto, CA: Stanford University Press.

Tucker, L., \& Bagwell, M. (1991). Television viewing and obesity in adult females. American Journal of Public Health, 81(7), 908.

Tucker, L., \& Friedman, G. (1989). Television viewing and obesity in adult males. American Journal of Public Health, 79(4), 516.

Vandelanotte, C., Sugiyama, T., Gardiner, P., \& Owen, N. (2009). Associations of leisure-time Internet and computer use with overweight and obesity, physical activity and sedentary behaviors: Cross-sectional study. Journal of Medical Internet Research, 11(3), 1-8.

Wang Q., Fink, E. L., \& Cai, D. A. (2008). Loneliness, gender, and parasocial interaction: A uses and gratifications approach. Communication Quarterly, 56, 87-110.

Warren, R., Gerke, P., \& Kelly, M. A. (2002). Is there enough time on the clock? Parental involvement and mediation of children's television viewing. Journal of Broadcasting \& Electronic Media, 46, 87-111.

Weissman, M. M., Orvaschel, H., \& Padian, N. (1980). Children's symptom and social functioning self-report scales: Comparison of mothers' and children's reports. Journal of Nervous Mental Disorders, 168(12), 736-740.

Wells, M. S., Widmer, M. A., \& McCoy, K. (2004). Grubs and grasshoppers: Challenge-based recreation and the collective efficacy of families with at-risk youth. Family Relations, 53(3), 326-333.

White, J. M., \& Klein, D. M. (2008). Family theories. Los Angeles, CA: Sage.

Zabriskie, R. B., \& McCormick, B. P. (2001). The influences of family leisure patterns on perceptions of family functioning. Family Relations, 50, 281-289. 
FAMILY MEDIA 